\title{
Cognitive appraisal of perceived threat of diabetes and adherence to self -management behaviors
}

\author{
Roger D. Carpenter \\ West Virginia University
}

Follow this and additional works at: https://researchrepository.wvu.edu/etd

\section{Recommended Citation \\ Carpenter, Roger D., "Cognitive appraisal of perceived threat of diabetes and adherence to self -management behaviors" (2008). Graduate Theses, Dissertations, and Problem Reports. 2687. https://researchrepository.wvu.edu/etd/2687}

This Dissertation is protected by copyright and/or related rights. It has been brought to you by the The Research Repository @ WVU with permission from the rights-holder(s). You are free to use this Dissertation in any way that is permitted by the copyright and related rights legislation that applies to your use. For other uses you must obtain permission from the rights-holder(s) directly, unless additional rights are indicated by a Creative Commons license in the record and/ or on the work itself. This Dissertation has been accepted for inclusion in WVU Graduate Theses, Dissertations, and Problem Reports collection by an authorized administrator of The Research Repository @ WVU. For more information, please contact researchrepository@mail.wvu.edu. 
Cognitive Appraisal of Perceived Threat of Diabetes and Adherence to Self-Management Behaviors

\section{Roger D. Carpenter}

Dissertation submitted to the School of Nursing at West Virginia University in partial fulfillment of the requirements for the degree of Doctor of Philosophy in Nursing

Cynthia A. Persily PhD, RN, FAAN, Chair

June H. Larrabee, PhD, RN Charlotte Nath, EdD, RN Irene Tessaro, DrPH, RN Heidi Putman, DSN, RN

$$
\text { School of Nursing }
$$

Morgantown, West Virginia

2008

Key Words: Diabetes, Adherence, Threat, Cognitive Appraisal 


\begin{abstract}
Cognitive Appraisal of Perceived Threat of Diabetes and Adherence to Self-Management Behaviors

Roger D. Carpenter
\end{abstract}

Background: Within adherence research, health beliefs have been identified as being significant predictors of adherence. Specifically, perceived threat as a health belief has received considerable attention. However, a gap in current knowledge exists in terms of understanding perceived threat of illness as an event that is appraised by the patient. Aim: The purpose of this exploratory, descriptive study was to examine cognitive appraisal of perceived threat of illness in relation to adherence to self-management behaviors in uninsured/under-insured persons with type 2 diabetes.

Method: A convenience sample consisted of 80 subjects being treated for type 2 diabetes mellitus at a free clinic in West Virginia between January 2008 and May 2008 meeting the following inclusion criteria: 1 ) age $\geq 18$ years, 2) diagnosis of type 2 diabetes, 3) the ability to read, write, or understand English, and 4) uninsured/underinsured and receiving care at a free clinic. Subjects were administered the Summary of Diabetes Self Care Activities and the Cognitive Appraisal of Health Scale.

Results: Characteristics of the study sample included a mean age of 50.4 years (range 23 to 64 years), with $27.4 \%$ men and $72.4 \%$ women. The majority of subjects were white (94.7\%), had diabetes for less than 10 years (82.9\%), and reported having one to two comorbidities. The sample followed recommendations for taking prescribed oral medications an average of 6.6 days/week, for general diet an average of 4.1 days/week, for specific diet 3.7 days/week, and for exercise an average of 2.9 days/week. The mean 
HbA1c $=7.56$. HbA1c levels of $7 \%$ or greater were found in $49.4 \%$ of the subjects. Several significant relationships were found between cognitive appraisal variables and self-management variables. Persons with diabetes in this study perceived their diabetes as more of a challenge than as threatening or causing harm or loss. Cognitive appraisal did predict variance in adherence to diet and HbA1c level. Cognitive appraisal did not predict adherence to oral medication taking or exercise recommendations.

Conclusion: The persons with diabetes receiving care at the free clinic from this study did not differ in their levels of adherence to self-management behaviors from other types of patients reported in the literature. This study highlights the need for more research exploring the issues that persons with diabetes have with adherence to self-management behaviors, especially diet and exercise recommendations. 


\section{TABLE OF CONTENTS}

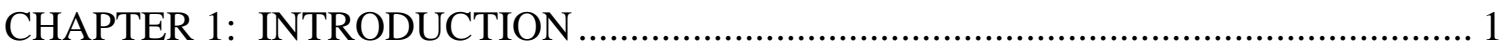

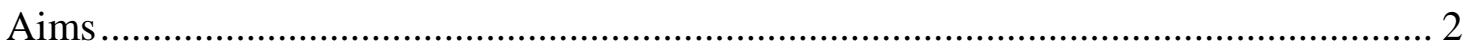

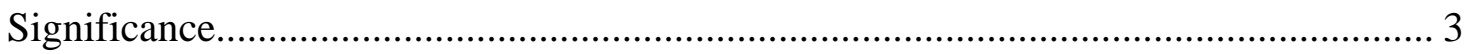

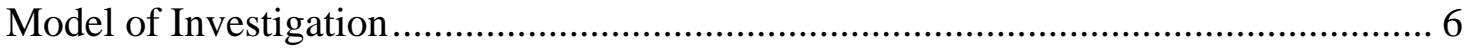

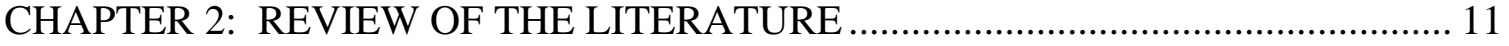

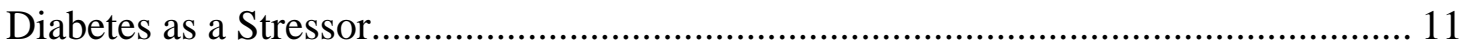

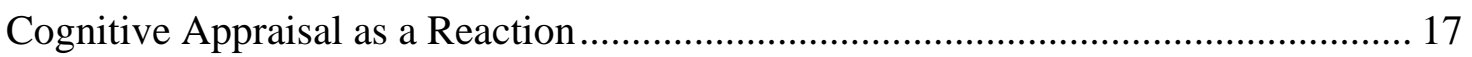

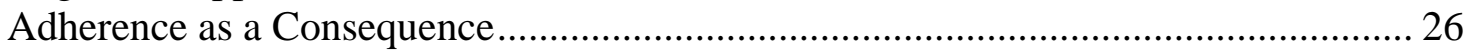

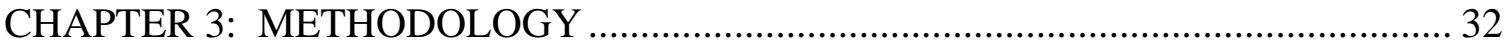

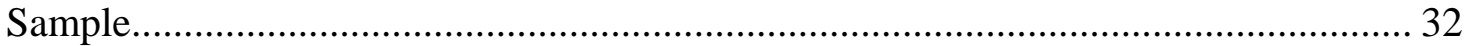

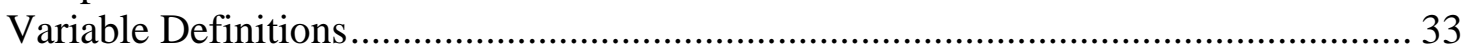

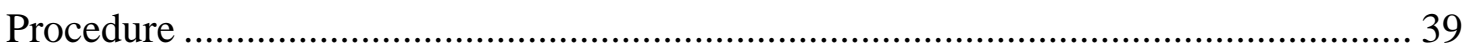

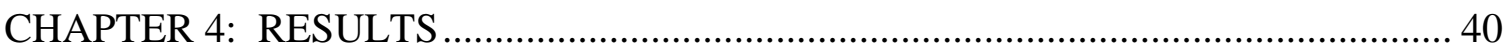

Factor Analysis: Cognitive Appraisal of Health Scale (CAHS) ................................. 42

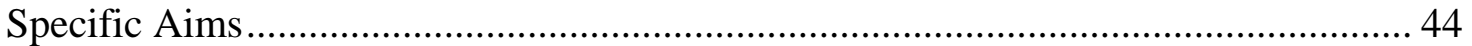

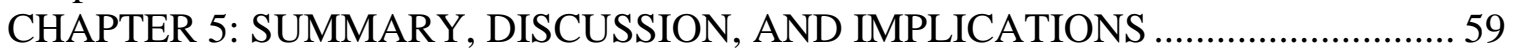

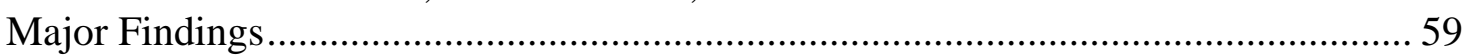

Study Findings and the Stress-Response-Sequence Model ..................................... 64

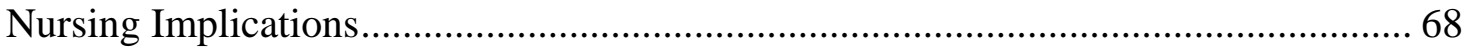

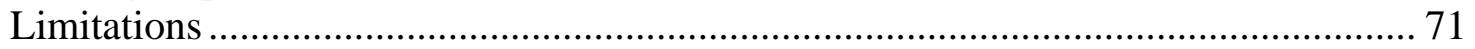

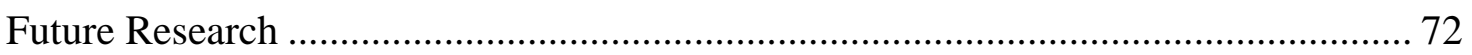

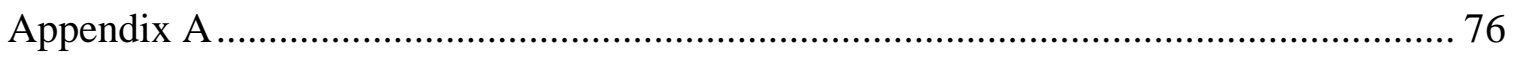

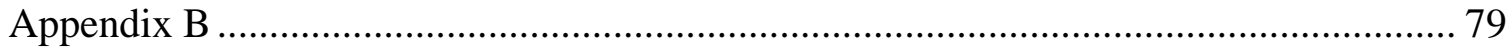

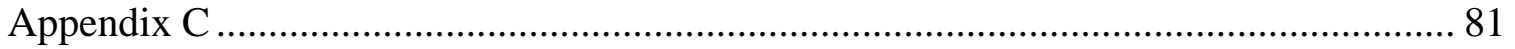

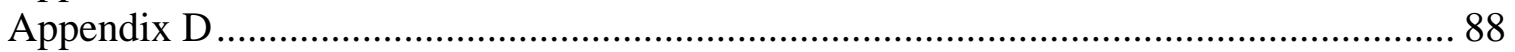

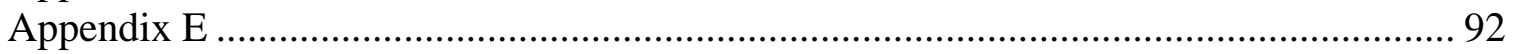

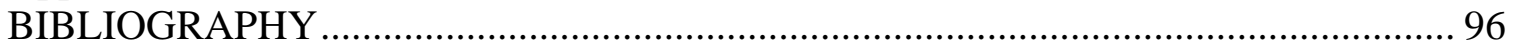




\section{LIST OF FIGURES}

Figure 1. Stress response sequence model .............................................................................................. 9

Figure 2. Cognitive appraisal and general diet .....................................................................................65

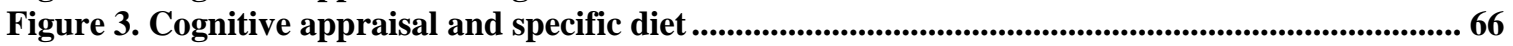

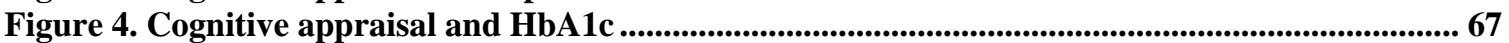

\section{LIST OF TABLES}

Table 1: Sample demographics

Table 2: Factor analysis of the items of the CAHS ........................................................................43

Table 3: Appraisal variables....................................................................................................44

Table 4: Correlations between primary and secondary appraisal variables.......................................... 45

Table 5: Diabetes self-management behaviors......................................................................................45

Table 6: HbA1c level and time since last level ...............................................................................46

Table 7: Correlations between primary appraisal and self-management behavior variables .............. 49

Table 8: Correlations between secondary appraisal and self-management behavior variables.......... 50

Table 9: Multiple regression analysis for general diet ............................................................. 53

Table 10: Multiple regression analysis for specific diet ................................................................ 55

Table 11: Multiple regression analysis for HbA1c .......................................................................58 


\section{CHAPTER 1: INTRODUCTION}

Diabetes mellitus is one of the major causes of disease morbidity and mortality in the United States and throughout the world. It is estimated that nearly 20.8 million people have diabetes in the United States, with 1.5 million new cases diagnosed in people 20 years or older in 2005 (Centers for Disease Control, 2005). It is the leading cause of cardiovascular disease, stroke, blindness, kidney disease, and lower-limb amputations in the United States. In 2005, the Centers for Disease Control estimated that diabetes cost the United States $\$ 132$ billion in both direct and indirect medical costs (Centers for Disease Control, 2005).

Diabetes mellitus and its associated complications accounts for a significant proportion of the chronic care provided by health care providers. A significant clinical problem encountered by health care providers in the care of individuals with diabetes mellitus is adherence to the prescribed medical treatment regimen (Beckles, et al., 1998; Donnan, MacDonald, \& Morris, 2002). Research has demonstrated that tight glycemic control can significantly reduce complications associated with diabetes (UKPDS, 1998a; UKPDS, 1998b). However, management of diabetes and tight glycemic control is complex, involving many factors such as diet, exercise, medication, access to care, and health beliefs. Additionally, since the management of diabetes is mostly done by patients

and families, self-management has become the mainstay of diabetes care. However, selfmanagement is complicated by issues related to patient adherence to treatment regimens.

Diabetes is a significant problem for the uninsured. Data collected from the 2000 Behavioral Risk Factor Surveillance System (BRFSS) revealed that among persons with diabetes under age 65 years, 11\% were uninsured (Nelson, Chapko, Reiber, \& Boyko, 
2005). Data collected from the third National Health and Nutrition Examination Survey

(NHANES III) suggest that 7\% of adults with diabetes under age 65 years of age are uninsured (Harris, 1999). Uninsured adults with diabetes are predominantly minority and low income and receive fewer preventive services than those with health insurance (Nelson et al., 2005: Ayanian, Weissman, Schneider, Ginsburg, \& Zaslavsky, 2000).

A significant body of research has focused on problems with treatment adherence being attributed to health beliefs (Horne \& Weinman, 1998). Within the broader agenda of adherence research, health beliefs have been identified as being significant predictors of adherence. Specifically, perceived threat as a health belief has received considerable attention in adherence research from many perspectives in multiple patient populations (Carpenter, 2005). However, a gap in current knowledge exists in terms of understanding perceived threat of illness as an event that is appraised by the patient.

\section{Aims}

The purpose of this exploratory, descriptive study was to examine cognitive appraisal of perceived threat of diabetes in relation to adherence to recommended selfmanagement behaviors in uninsured persons with type 2 diabetes. The research question asked was "What is the relationship between cognitive appraisal of perceived threat of diabetes and adherence to recommended self-management behaviors of uninsured persons with diabetes?” Specifically, the aims of this study were:

1. To describe the cognitive appraisal of perceived threat of diabetes in uninsured persons with diabetes.

2. To describe the levels of diabetes self-management behaviors, including diet, exercise, and medication taking in uninsured persons with diabetes. 
3. To describe levels of hemoglobin A1c in uninsured persons with diabetes.

4. To analyze the relationship between the cognitive appraisal of perceived threat of diabetes and self-management behaviors of diet, exercise, and medication taking in uninsured persons with diabetes.

5. To analyze the relationship between cognitive appraisal of perceived threat of diabetes and hemoglobin A1c levels, controlling for the self-management behaviors of diet, exercise, and medication taking in uninsured persons with diabetes.

\section{Significance}

There are several reasons for studying cognitive appraisal of perceived threat of diabetes in relation to adherence to recommended self-management behaviors in uninsured persons with diabetes. First, persons with diabetes have issues with adherence to recommended self-management behaviors. Secondly, the issue of access to health care and the ability to pay for care has direct impact on adherence. And finally, health beliefs related to perceived threat of illness have been identified as being significant predictors of adherence.

\section{Treatment Adherence and Persons with Diabetes}

The complexity of diabetes, its management, and the need for the patient to practice self-management makes adherence to diabetes treatment challenging and often difficult to achieve. The nature of diabetes requires that it be managed continuously throughout the course of daily life activities. The disease does not provide periods of remission where one can have reprieve from managing the disease. Additionally, the treatment plans for diabetes management are complex, involving multiple factors and 
treatment modalities, including diet, exercise, blood glucose monitoring, medications, education, and follow up and preventive care.

Adherence issues related to treatment regimen in the management of diabetes have been well documented. One out of five Americans with diabetes does not practice any self-monitoring of blood glucose (SMBG), about three out of four have never heard of hemoglobin A1C (HbA1C), and 25\% either make no annual visit to a health care provider for diabetes care, or visit but are unaware why (Beckles et al., 1998). Adherence with medications has been documented to be problematic with persons with diabetes. Only one third of patients with type 2 diabetes obtain enough prescription drugs to enable them to take their medication $90 \%$ of the time (Donnan et al., 2002).

Adherence to treatment regimen in diabetes is important for several reasons. First, adherence to the treatment regimen can help prevent complications of diabetes. Second, adherence is necessary for clinicians to be able to evaluate the effectiveness of therapeutic regimens. And finally, non-adherence is expensive in terms of financial burden to health care systems and society.

\section{Uninsured Status and Diabetes}

The association between being uninsured and having adverse clinical consequences is well documented. Long-term uninsured adults report greater unmet health needs when compared with insured adults, including not being able to see a physician and receiving routine check ups (Ayanian et al., 2000). Lack of insurance is a major barrier to obtaining health care for important medical conditions. The uninsured are less likely to receive medical care, and are more likely to say they do not receive care even though they feel it is needed (Baker, Shapiro, \& Schur, 2000). 


\section{Perceived Threat and Adherence}

Patients have multiple reasons based on their health beliefs for why they consciously or unconsciously choose to adhere to medical advice. The health belief of perceived threat of illness has been studied extensively in the domain of adherence research. Falling within the context of health beliefs serving as predictors of adherence, perceived threat of illness has been identified as a significant factor that influences decisions made by patients in relation to treatment adherence. However, there are limitations in the existing body of research related to perceived threat of illness and its effects on treatment adherence. Although a vast number of studies have explored this concept, limited studies measure perceived threat of illness as a cognitive appraisal (Carpenter, 2005).

Perceived threat has been cited mostly in studies that focus on health beliefs or utilize a stress and coping paradigm. Within these studies, perceived threat is typically measured with instruments designed to assess an individual's cognitive appraisal of a stressful situation (Carpenter, 2005). However, studies often suggest that the individual makes an "on-off" or "yes-no" rational decision whether to adhere with treatment, based on the risks and benefits of that decision. However, the cognitive appraisal processes are much more complex. Cognitive appraisal is a reaction in which an individual evaluates an event in terms of how it affects well-being. Additionally, cognitive appraisal is influenced by antecedent conditions, including: (a) person variables, such as values, commitments, goals, and general beliefs, and (b) environmental variables, such as demands, resources, constraints, and temporal aspects (Lazarus \& Folkman, 1987). 
The concept of cognitive appraisal has significance to adherence research. Being the central construct from the transactional model of stress and coping, the assumption that cognitive appraisal processes are involved in how an individual reactions to the environment is widely accepted (Croyle, 1992). Appraisal processes generate emotions, which in turn, influence coping mechanisms (Folkman \& Lazarus, 1988; Smith \& Lazarus, 1993). Therefore, the relationship between cognitive appraisal and adherence needs to be explored. Responses to perceived threat of illness are influenced by how the demands of a situation are appraised. Following this line of thinking, it should be possible to explore adherence in terms of the appraisal of illness and the decisions made by patients when confronted with the threat of illness.

Model of Investigation

The theoretical model of investigation used to guide this study was the StressSequence Response model (Elliot \& Eisdorfer, 1982). Many models have been proposed for the study of a stressor such as diabetes mellitus. However, most models focus on the reaction to a stressor, or an individual's stress response. The theoretical model used to guide this study is the Stress-Response Sequence (SRS) model (Figure 1). This model was described in the introduction to a report commissioned by the Institute of Medicine on the effects of stress on human health. This model goes beyond the stressor and the response to include mediators and consequences.

This model divides the stress response into four interrelated components: stressors, reactions, consequences, and mediators. Broadly defined, stressors are activators of the sequence, and can include internal or external events or conditions that change an individual's present state. In this study, the stressor under investigation is the 
threat of diabetes. Reactions are the biological or psychological responses an individual has to the stressor. In this study, reactions are considered to include the cognitive appraisal of the threat of diabetes. Consequences are the sequelae to the reactions, and can be biological, psychological, or sociological. In this study, consequences are the selfmanagement behaviors of diet, exercise, and medication taking. Mediators are personal or environmental variables that account for the wide range of responses different individuals have in response to the same stressor. Mediators under investigation in this study are age, time since diagnosis, gender, co-morbidities, and education.

This model was developed for use by healthcare professionals to describe, predict, or control biological and psychological stressors for many patient populations. The model is generic enough to fit a large number of patient populations and environmental and situational contexts. In applying the model to clinical practice, internal and external events or stressors lead to reactions that can be mediated by many unique personal or situational factors. The results are positive or negative consequences of the reactions. The model allows healthcare professionals to identify mediators or points of interventions at many points within the sequence as a basis for directing practice.

The most frequently cited use of this model has been in the study of stress in pediatric oncology nurses by Hinds and colleagues (Hinds, et al., 1990; Hinds, et al, 1994; Hinds, Quargnenti, Hickey, \& Mangum, 1994; Hinds et al., 1998; Olson et al., 1998; Hinds et al., 2003). Previous studies using the SRS model to predict role consequences in pediatric oncology nurses have found no significant relationships between the components of the SRS model (Hinds et al., 1998). A revised SRS model was proposed, adding a role-related meaning scale to the reactions component of the 
model. Again, the components of the model did not predict roles consequences in pediatric oncology nurses (Hinds et al., 2003).

Other investigations have used the SRS model as the conceptual basis for the study. The SRS model was used in a study exploring the relationships among stressful life experience, mood, T-cell counts, and genital herpes simplex (HSV) recurrence. Results supported a model linking depressive mood, CD8+cell, and HSV recurrence, thus supporting the theoretical relationship between the concepts of the model (Kemeny, Cohen, Zegans, \& Conant, 1989). Additionally, the SRS model served as the conceptual basis for a study of psychological distress and milk volume in lactating mothers (Hill, Aldag, Chatterton, \& Zinaman, 2005). This study explored the relationships between childbirth (stressor), physical or psychological reactions to childbirth, primary and secondary mediators, and maternal milk volume (consequences).

The SRS model has also been adapted for specific research. Kenney (2000) used an adapted version of the SRS model to study the effect of relationships among women's stressors, personality traits (mediators), and health problems (consequences). The adapted model viewed health as "inner balance", which was determined by the relationships between stressors, mediators, and consequences, thus supporting the theoretical relationship between the concepts of stressors, mediators, and consequences.

Understanding the effects of appraisal of perceived threat of illness on selfmanagement behaviors in diabetic patients seeking care in a free clinic may help explain the reasons why patients have difficulty with self-management of their diabetes including diet, exercise, and medication taking. In addition to gaining knowledge about how 
Figure 1. Stress response sequence model

\section{Framework for Interaction Between the Individual and the Environment}

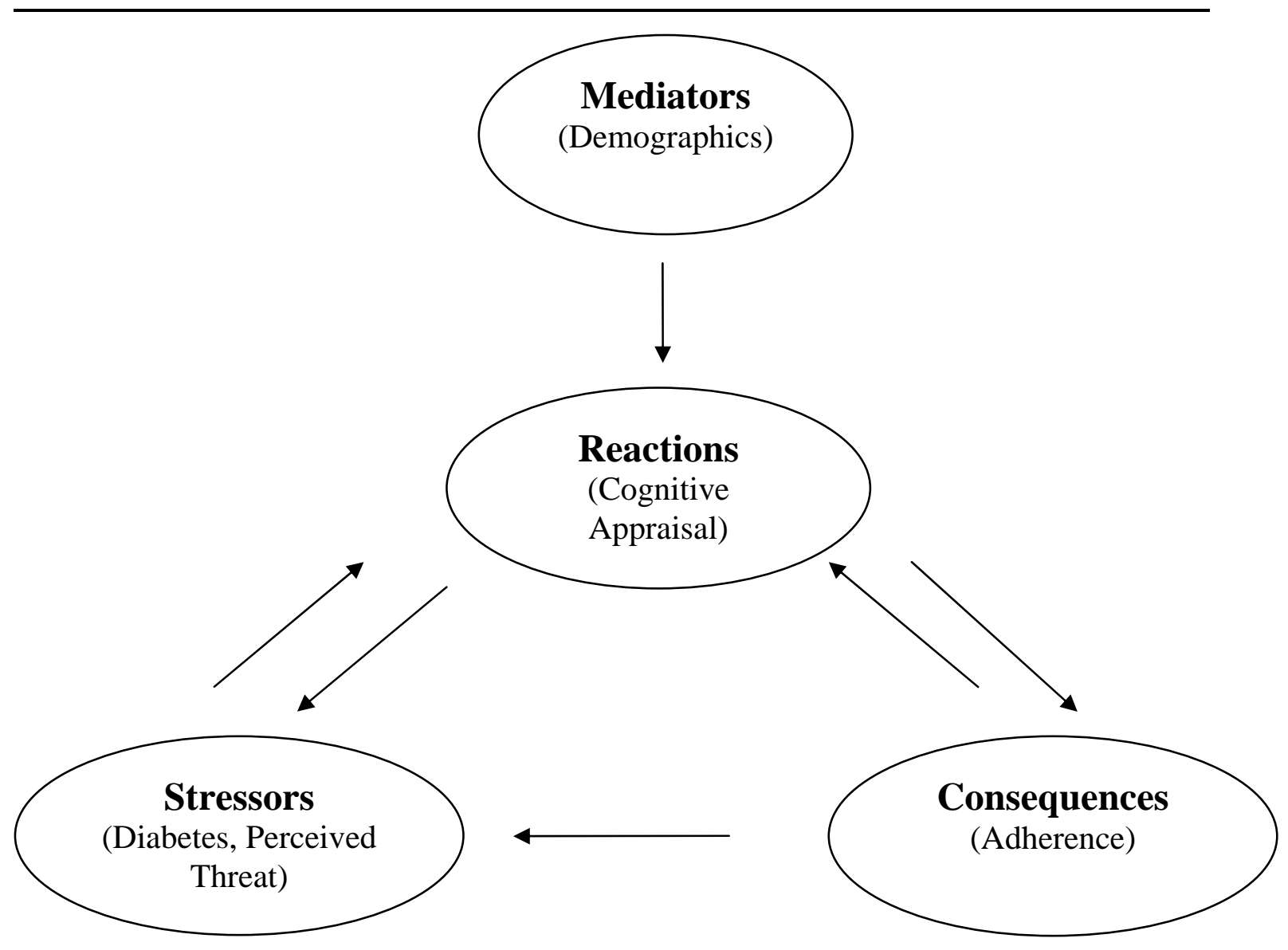

Adapted from "Stress and Human Health: Analysis and Implications of Research.” By G. Elliot and C. Eisdorfer, 1982. New York: Springer Publishing Company. Author permission granted, October 22, 2007. 
patients cognitively appraise the threat of diabetes, measuring both primary and secondary appraisals may also provide opportunities to screen for those at risk for nonadherence by identifying inaccurate primary appraisals (for example, underestimating the threat of an illness or behavior) and secondary appraisals that may be suboptimal (for example, ineffective coping resources, such as denial, in response to primary appraisal of threat of illness).

Although much has been learned about predictors and factors related to nonadherence, a significant amount of ambiguity and gaps in knowledge exist in this large body of research. Health care providers need to know more about the reasons underlying patient decision making in regard to treatment advice. Identifying reasons why patients do not adhere to treatment regimens is one of the major goals of diabetes care. 


\section{CHAPTER 2: REVIEW OF THE LITERATURE}

The purpose of this exploratory, descriptive study was to examine cognitive appraisal of perceived threat of diabetes in relation to adherence to self-management behaviors in uninsured persons with type 2 diabetes. This chapter will review the literature related to the cognitive appraisal of perceived threat of diabetes mellitus as related to adherence. The review will be structured in accordance with the theoretical model of investigation used to guide this study - the Stress-Sequence Response model (Elliot \& Eisdorfer, 1982). Following this model, the review will describe the literature supporting diabetes mellitus as a stressor, cognitive appraisal as a reaction, and adherence as a consequence.

\section{Diabetes as a Stressor}

There are multiple stressors that occur across the life span of the person with type 1 or type 2 diabetes mellitus. Holmes (1986) describes the life span of the person with diabetes in three phases: (a) First phase: the year after diagnosis which is characterized by emotional upset due to the diagnosis of diabetes, (b) Mid phase: a phase of relative well being and functioning that usually lasts several years, and occasionally, several decades, and (c) Third phase: the time when the person needs to make allowances for one or more permanent physical complications. Multiple stressors including the threat on life expectancy, acute and chronic complications, and the demands of self-management of diabetes occur in all phases of this disease.

\section{Mortality}

Mortality rates for persons with insulin-dependent diabetes mellitus (IDDM) are five to seven times that of the general population for males, and nine to twelve times that 
for females. Life expectancy is reduced by 15 years, with the majority of deaths occurring in middle and late adulthood. Cause of death changes with longer duration of IDDM. Early after diagnosis, acute coma is the leading cause of death, followed by renal disease in the middle years, and cardiovascular disease after 30 years of IDDM. The strongest predictor of survival is IDDM patients is metabolic control (Harris, 1995).

Life expectancy for middle-aged persons with non-insulin-dependent diabetes (NIDDM) is reduced by five to ten years. However, the mortality impact of NIDDM has been greatly underestimated, with cause of death being attributed to complications of diabetes as opposed to the primary disease. The four leading causes of death in persons with NIDDM are heart disease (approximately 50\%), diabetes (13\%), malignant neoplasms (13\%), and cerebrovascular disease (10\%). Reduced life expectancy is greater for diabetic women than men, and for those with complications of diabetes (Harris, 1995).

\section{Complications}

The complications associated with diabetes mellitus are numerous, and range from acute life-threatening, to chronic-disabling. These complications and the threat of these complications can place significant stress on the patient with this disease. Major classifications of diabetes-associated complications include disability, acute metabolic complications, vision disorders, neuropathy, kidney diseases, peripheral vascular disease, lower extremity foot ulcers and amputations, heart disease, stroke, digestive diseases, infections, oral complications, and psychosocial complications.

Disability affects a large number of persons with diabetes. Persons with diabetes report disabilities such as activity limitations, being unable to carry on their major 
activity, and restricted activity days at a rate of two to three times higher than persons without diabetes. The greatest impact affects the person's ability to work and remain employed. Additionally, persons with diabetes report lower self-reported health status (Harris, 1995).

The acute complications of diabetes include diabetic ketoacidosis (DKA), hyperosmolar nonketotic coma (HNC), lactic acidosis, and hypoglycemia. These complications require immediate medical intervention, usually involve hospitalization, and are life-threatening. Mortality rates range from $9 \%$ to $14 \%$ for DKA, and 10\% to 50\% for HNC (Harris, 1995).

The majority of complications from diabetes are long-term in nature. Vision disorders include diabetic retinopathy, which is the leading cause of new cases of blindness in the United States. Neuropathy is very common in both forms of diabetes, and affects anywhere from $30 \%$ to $70 \%$ of all patents with diabetes. Kidney diseases include end-stage renal disease, with persons with diabetes being the fastest growing group of renal dialysis and transplant recipients. Peripheral vascular disease and the associated lower extremity foot ulcers and lower limb amputations continue to be an increasing problem for the person with diabetes. Diabetes is responsible for more than half of all non-traumatic lower limb amputations in the United States. Heart disease and stroke are major problems for the persons with diabetes, and both appear much earlier in life than in non-diabetics. The reporting of digestive diseases, including ulcers, diverticulitis, symptoms of irritable bowel, and gall stones is much more common in the person with diabetes than in the general population. Infections, including asymptomatic bacteriuria, lower extremity infections, infections in surgical wounds, and group B 
streptococcal infections are more common in persons with diabetes. Psychosocial complications, such as depression, are common with research suggesting associations between depression and severity of diabetes (Harris, 1995).

\section{Self-management of Diabetes as a Stressor}

The management of diabetes takes place primarily in the setting of an individual's daily life, thus making self-management a major emphasis in diabetes care. The selfmanagement of diabetes presents many stressors to the person with diabetes. The treatment of diabetes is complex, involving medications, monitoring activities, and significant life style modifications. Within the diabetes literature, the terms self-care and self-management are often used interchangeably. Self care has been described as the daily regimen tasks an individual performs to manage diabetes and to promote or restore health with support of health care professionals (Weinger, Butler, Welch, La Greca, 2005). It has also been proposed that the responsibility for self care rests on three characteristics: (a) the patient makes the important choices about their lifestyle behaviors, (b) the patient is in control of their diabetes self-management, and (c) the patient experiences the consequences of their choices related to self care (Anderson \& Funnell, 2000). For purposes of this study, the term self-management will be used. Self management has been defined as including: (a) knowledge of the importance of selfmanagement, (b) instructions in lifestyle behaviors including diet, exercise, medication management, self-monitoring of blood glucose (SMBG), and complication identification and prevention, and (c) the development of coping skills (Norris, Engelgau, \& Narayan, 2001; Norris, Lau, Smith, Schmid, \& Engelgau, 2002). 
Stress related to having diabetes is common due to the burdensome and nonending demands of self-management. In a study of 815 primary care clinic adult patients with type 2 diabetes, important determinants of diabetes-related emotional distress were burden of self-care, perceived need to adhere to diet, exercise and medications, and level of hemoglobin A1c. Additionally, levels of emotional distress were significantly higher for insulin-treated compared with oral medication and diet treated patients (Delahanty et al., 2007).

In a study of 451 female patients with type 1 and type 2 diabetes mellitus, diabetes-related emotional distress was reported in over half the sample, with serious concerns about the possible development of long-term complications, and feelings of guilt and anxiety regarding poor adherence to diabetes treatment regimen. Additionally, diabetes-related emotional distress was found to be a unique contributor to adherence to self-care behaviors after adjusting for age, duration of diabetes, and general emotional distress (Polonsky et al., 1995).

Integrating the lifestyle changes required to manage diabetes into an existing lifestyle has been described as challenging. In a study exploring the lived experience of integrating type 2 diabetes mellitus treatment recommendations, maintaining balance between structure and flexibility, fear and hope, conflict and acceptance, and diabetes and life were significant challenges identified by diabetics (Whittemore, Chase, Mandle, \& Roy, 2002). In a study of adult patients with type 2 diabetes mellitus, challenges to selfmanagement were described in terms of barriers. These barriers included lack of specific knowledge about diet and lack of understanding of the plan of care. Additionally, subjects experienced helplessness and frustration from lack of glycemic control and 
continued disease progression despite adherence to a complex treatment plan (Nagelkerk, Reick, \& Meengs, 2006).

Management of diabetes needs to be integrated into the daily lives of those with diabetes, and this presents many challenges including emotional distress, overwhelming treatment burden, and difficulties in balancing life with diabetes management. As noted in a report from the Diabetes Initiative of The Robert Wood Johnson Foundation (Fisher et al., 2007), self-management alone does not equip the person with diabetes to autonomously manage their diabetes. Research shows that self-management is dependent on on-going follow-up and reinforcement for the rest of a person's life.

\section{Insurance Status as a Stressor}

The association between being uninsured and adverse clinical consequences is well documented. Long-term uninsured adults report greater unmet health needs when compared with insured adults, including not being able to see a physician and receiving routine check ups (Ayanian et al., 2000). Lack of insurance is a major barrier to obtaining health care for important medical conditions. The uninsured are less likely to receive medical care, and are more likely to say they do not receive care even though they feel it is needed (Baker et al., 2000). Insurance status is a serious problem for many persons with diabetes. Data collected from the 2000 Behavioral Risk Factor Surveillance System (BRFSS) revealed that among diabetic persons under age 65 years, 11\% were uninsured (Nelson et al., 2005).

With the emphasis on self-management of diabetes in the home environment, insurance status is not only a significant problem for persons with diabetes, but also a significant stressor. Uninsured adults with diabetes are predominantly minority and low 
income. Compared with adults under age 65 with private insurance, the uninsured person with diabetes under age 65 years was less likely to have received the preventative services of dilated eye exams, foot exams, and HbA1c testing. Additionally, uninsured persons with diabetes report the lowest rates of daily home blood glucose monitoring, and participation in diabetes education classes (Beckles et al., 1998: Ayanian et al., 2000; Nelson et al., 2005). The poor with diabetes (uninsured or under-insured) have worse glycemic control, lower adherence rates to self-management activities, and more knowledge deficits related to self-management and adherence (Tu \& Morrison, 1996).

For many individuals with diabetes, the stressors associated with the disease are constant and significantly impact daily life. However, not everyone perceives the stressors of diabetes in the same way or with the same significance. How an individual perceives the threat of these stressors has been identified as a significant factor in adherence to treatment regimen.

\section{Cognitive Appraisal as a Reaction}

\section{Perceived Threat}

Historically, the literature has examined adherence as a solitary construct. However, according to Dunbar-Jacobs and Schlenk (2001), poor adherence can take on multiple forms and patterns, and it is therefore likely that predictors of adherence might vary among these multiple forms. A significant body of research has focused on problems with treatment adherence being attributed to intentional decision or motivation issues on the part of the patient. Research has suggested that multiple factors influence the decisions made by patients in relation to treatment adherence. Of particular interest is the concept of perceived threat of illness. Based on a review of the literature, the concept 
of perceived threat has been defined as the anticipation of harm based on the cognitive appraisal of an event or cue that is capable of eliciting an individual's stress response (Carpenter, 2005). Falling within the context of health beliefs serving as predictors of adherence, perceived threat of illness is one of many factors that influence decisions made by patients in relation to treatment adherence.

The concept of perceived threat of illness has been studied extensively in the domain of compliance and adherence research. Perceived threat has been cited mostly in studies that focus on health beliefs or utilize a stress and coping paradigm. Within these studies, perceived threat is typically measured with instruments designed to assess an individual's appraisal of a stressful situation.

The vast majority of research and measurement of the concept of perceived threat has utilized the health belief model (HBM). According to the HBM (Rosenstock, Strecher, \& Becker, 1988), health behavior is a function of an individual's personal beliefs about the perceived threat of disease and an appraisal of the risks/benefits of the recommended course of action. These beliefs are influenced by many factors, including how an individual appraises a situation. Evidence suggests that the cognitive components specified in the HBM may be predictors of adherence in some situations (Horne \& Weinman, 1998). Within these HBM studies, perceived threat is typically measured as a uni-dimensional concept. Most HBM studies suggest that the individual makes an "onoff” rational decision whether to comply with treatment, based on a cost-benefit analysis of the risks and benefits of that decision. However, many factors may influence an individual's health beliefs regarding their state of health. Therefore, greater exploration of the cognitive processes surrounding the concept of perceived threat is warranted. 
Perceived threat has also been investigated and measured in the field of cognitive psychology. The most commonly cited model of investigation within the cognitive psychology literature is the transactional model of stress and coping as presented by Lazarus and Folkman (1984). Within this model, perceived threat is measured with tools that assess the cognitive appraisal of a threatening situation.

\section{Cognitive Appraisal}

Cognitive appraisal refers to the process that an individual uses to constantly evaluate what is happening to them from the standpoint of its significance for their well being (Lazarus \& Folkman, 1987). There are two major forms of appraisal: (a) primary appraisal, and (b) secondary appraisal.

In primary appraisal, the individual evaluates a specific transaction (or event) with respect to well-being. The individual decides if the event is irrelevant (no significance for well-being), benign-positive (does not tax or exceed personal resources and signals only positive consequences), or stressful. Stressful appraisals include harm, threat, and challenge. Primary appraisal is shaped by an array of personal and situational factors, such as personal beliefs and commitments.

Secondary appraisal involves the evaluation of coping resources and options, and addresses the question of "What can I do?” Answering this question becomes very important when there is a primary appraisal of harm, threat, or challenge. Potential coping resources include physical (such as an individual's health, energy, and stamina), social (an individual's social network and support systems), psychological (beliefs to sustain hope, skills for problem solving, self-esteem, and morale), and material assets (money, tools, and equipment) (Folkman, 1984). 


\section{Cognitive Appraisal and Illness}

Tools have been developed that measure cognitive appraisal of an illness situation, or capture the meaning of an illness situation in terms of cognitions. These tools have been used in studies examining chronically ill or terminally ill individuals.

The Meaning of Illness Questionnaire (MIQ) was designed to quantify the degree to which individuals apply a mix of appraisals to life circumstances (Browne et al., 1988). This tool also captures appraisals of an individual's coping resources used in an effort to manage life circumstances in a manner congruent with their beliefs about preferred behaviors. Specifically, subjects are asked about their coping energy and satisfaction with outlook and behavior under the stressful circumstance. The MIQ contains 33-items. Each item is rated on 3-point or 7-point scales ranging from "no" or "not at all” to "a great deal”. Primary appraisal items address harm, threat, and challenge; secondary appraisal items address expectancy and controllability. Two other open-ended questions concern a person's previous and current life beliefs and commitments. Preliminary and additional support for content, criterion, and construct validity has been described. The tool is not meant to give a total meaning score, but rather is meant to be used for the separate subscales. Therefore, tests of internal consistency are not applicable since each subscale is designed to elicit a discrete meaning an individual

may give to illness. However, test-retest reliability kappas ranged from .45 and 1.00, with the majority falling between .60 and .77 (Brown et al., 1988). Validity testing using principal component factor analysis produced five factors that support conceptual internal consistency of the MIQ. Inter-item correlations of these factors were low, ranging from .04 to .46 , indicating independence of factors and offering support for construct validity. 
Content validity testing of the factor structure of the questionnaire supports the theoretical assumptions underlying the instrument (Brown et al., 1988).

The MIQ has been used in a variety of studies examining appraisal components during an experience with illness. Most researchers utilize only part of the MIQ. Examples of use of the MIQ include studies exploring outcome predictors in cardiac patients (Dunbar, Jenkins, Hawthorne, \& Porter, 1996; Dunbar et al., 1999), sexual behavior in HIV positive women (Bova \& Durante, 2003), illness appraisal in older women (Nesbitt \& Heidrich, 2000), psychological adjustment of critically injured patients (Grossman et al., 2000), and adherence in diabetics (Ford, Havstad, Brooks, \& Tilley, 2002). Alpha coefficients for the MIQ subscales are reported to range from .59 to .90 in these studies.

The Appraisal of Illness Scale (Oberst, Hughes, Chang, \& McCubbin, 1991) was designed to measure stress appraisal in chronic illness. Initially used in studies conceptually guided by a cognitive appraisal model of stress and coping, this 27-item scale taps elements of four types of stressful appraisals of the illness situation: threat, loss, financial strain, and overall stressfulness. The intensity of each item is measured by a 5-point Likert-type scale, with response choices ranging from "very false” to "very true”. Higher scores indicate more stressful appraisals. Internal consistency and construct validity have been reported. Researchers using this tool have reported internal consistency coefficients ranging from .86 to .95 . Factor analysis of this scale yielded four factors accounting for $65 \%$ of the total variance: threat, loss, financial strain, and general stressfulness (Oberst et al., 1991). Reading level of the instrument was assessed at the fourth grade level (Northouse et al., 2002). 
Appraisal of Illness Scale has been used in the study of stress appraisals in cancer patients (Munkres, Oberst, \& Hughes, 1992; Oberst et al., 1991), outcomes in chronic pain patients (Pellino \& Oberst, 1992), and quality of life in breast cancer patients (Northouse et al., 1999; Northouse et al., 2002; Northouse, Kershaw, Mood, \& Schafenacker, 2005). However, the AIS has had limited use in research, and limited reporting of psychometric data.

The Cognitive Appraisal of Health Scale (CAHS) (Kessler, 1998) was designed to measure the dimensions of primary and secondary appraisal associated with healthrelated events. The primary appraisal scales include items that measure threat, harm/loss, challenge, and benign/irrelevant appraisals. The secondary appraisal scales include items measuring coping options and resources. Based on the transactional model of stress and coping, the premise of this instrument is that an individual could appraise a potentially stressful event in multiple ways. It was also designed with the knowledge that few researchers have measured both primary and secondary appraisal at the same time. Initial support for reliability and validity testing for this instrument was gathered in a study of 201 women with breast cancer. A factor analysis of the 28 items produced a four-factor solution that explained $60 \%$ of the total variance and represented the primary appraisal dimension. Correlations between primary and secondary appraisals were consistent with theoretical predictions $(\mathrm{p}<.01)$ as described by Lazarus and Folkman (1984). Internal consistency estimates of the primary appraisal scales were all greater than .70.

Additional psychometric testing using confirmatory factor analysis produced a three-factor model that accounted for $55.48 \%$ of the variance and represented three of the 
four original primary appraisal dimensions (Ahmad, 2005). The three factors kept in this model were threat, harm/loss, and challenge. This reduced the instrument to a 13 item instrument. Internal consistency for the total scale produced a Cronbach's alpha of .70. Internal validity was confirmed by principal factor analysis. Construct validity was confirmed through structural equation modeling.

The majority of research studies measuring appraisal of perceived threat have been predominantly HBM studies, using an item or a subscale that measures threat as perceived susceptibility or vulnerability. These scales are typically designed by the individual researcher and tailored to address the specific population and phenomenon being studied (Carpenter, 2005). Within this method of measurement, perceived threat is typically measured as a uni-dimensional construct, with scales measuring varying degrees of perceived threat. Because of the variability and inconsistency in the appraisal scales within HBM research, results of studies range from significant, suggestive, to not supported, depending on the research and elements studied within the model (Carpenter, 2005).

\section{Cognitive Appraisal and Adherence}

When an individual encounters a situation that is appraised as harmful, beneficial, or stressful, the situation is appraised in terms of relevance to personal goals and the well being of the individual. Understanding how an individual appraises potentially stressful events is important when facing the stressor of diabetes diagnosis, treatment, and selfmanagement.

However, cognitive appraisal has not been well studied (Kessler, 1998). The measurement of cognitive appraisal is a relatively new area of study, and most appraisal 
scales have been developed within the last 15 years (Ahmad, 2005). Measures of cognitive appraisal of perceived threat have been applied to research investigating the coping resources and appraisal of stressors in individuals experiencing chronic illness; however, most studies have utilized a measure of cognitive appraisal that is researcher constructed specifically for the study, and does not measure cognitive appraisal as theoretically described (Carpenter, 2005).

Four studies were found that explored cognitive appraisal and adherence. However, three of these studies used a researcher-constructed tool to capture a dimension of appraisal that was uni-dimensional, or have used only selected items or subscales of larger tools intended to measure both primary and secondary appraisal components. By far, most studies have measured primary appraisal, with little to no recognition of secondary appraisal.

In a study exploring perceptions about diabetes among African Americans and white Americans with diabetes, Ford et. al. (2002) used three subscales of the Meaning of Illness Questionnaire (MIQ) to measure appraisal of impact, loss, and stress associated with having diabetes. With a limited sample size $(\mathrm{N}=45)$, findings indicated that African Americans had a greater sense of loss associated with diabetes than whites $(\mathrm{p}<.05)$, concluding that perceptions of diabetes may vary by race. Although this study measured appraisal, it only measured primary appraisal.

In a study examining the appraisal of diabetes health risks and adherence in an ethnic minority sample of 74 adolescent patients with type 1 diabetes, HBM scales measuring perceived severity and susceptibility to diabetic complications were used to assess appraisal of threat of diabetes (Patino, Sanchez, Eidson, \& Delamater, 2005). 
Results indicated that consistent with prior studies, the appraisal of risk was higher for complications occurring to someone else with diabetes other than self. As in most HBM studies, the measure of appraisal focused on primary appraisal only.

In a study examining the relationship between adherence to breast self-exam (BSE) practice and cognitive appraisal, coping and emotional distress, 80 women with first-degree relatives who were breast cancer patients and 47 matched controls completed researcher-constructed measures of cognitive appraisal (Cohen, 2002). The primary appraisal component measured perceived risk for breast cancer, and the secondary appraisal component measured perceived control over breast cancer prevention. Findings indicated that in women with first-degree relatives, greater adherence to BSE practice was associated with higher perceptions on control over prevention, higher risk for breast cancer, and higher levels of state anxiety. Although this study measured both primary and secondary appraisal, the tool was researcher constructed and did not capture cognitive appraisal in its entirety, nor were psychometric properties of the measures reported.

In a study investigating the health beliefs of 118 young persons aged 16-25 years with type 1 diabetes, an expanded version of the health belief model, incorporating measures of control and self-efficacy, was tested (Gillibrand \& Stevenson, 2006). Findings suggested that high internal locus of control and high levels of self-efficacy predicted benefits of adhering to self-care regimen, but the final model explained only $12 \%$ of the variance in the young person's adherence to diabetes self-care regime. Additionally, as in other studies, both primary and secondary appraisal was measured, but the items came from multiple tools and did not measure cognitive appraisal in its entirety. 
Although these studies do measure cognitive appraisal, they used a subscale of a larger tool designed to measure appraisal, or used a researcher-constructed tool to capture a dimension of appraisal. Measures of cognitive appraisal must be multi-dimensional to capture all aspects of both primary and secondary appraisal. Only a few researchers have measured both primary and secondary appraisals at the same time (Kessler, 1998).

Finally, few research studies (Cohen, 2002; Ford et. al., 2002; Patino et. al., 2005;

Gillibrand \& Stevenson, 2006) identified in the literature studied cognitive appraisal of perceived threat in relation to adherence research.

\section{Adherence as a Consequence}

A significant clinical problem encountered in the care of persons with diabetes is adherence to self-management regimen. Although all components of self-management are important in the effective management of diabetes, diet, exercise and medication taking have received considerable attention in adherence research due to the influence these activities have on glycemic control (Rewers \& Hamman, 1995; Wing et al., 2001, ADA, 2008).

\section{Diet}

Adhering to dietary recommendations for persons with type 2 diabetes has been shown to be problematic. In a nationally representative sample of 2056 patients with diabetes, only 64\% either "always" or "usually" followed their recommended diet plan (Ruggiero et al., 1997). Findings from the NHANES III showed that in a sample of 1480 adults with type 2 diabetes, nearly two-thirds consumed greater than $30 \%$ of their daily calories from fat and greater than $10 \%$ of total calories from saturated fat, and that $82 \%$ of the sample were either overweight or obese (Nelson, Reiber, \& Boyko, 2002). In a 
sample of 347 patients with type 2 diabetes from the Diabetes Outcomes in Veterans Study, 69.7\% did not optimally adhere to dietary standards as described by the American Diabetic Association, with dietary adherence being especially poor in subjects with metabolic syndrome and/or obesity (Murata et al., 2004). Results from the Diabetes Attitudes, Wishes, and Needs (DAWN) study, a large cross-national study with the purpose of identifying the role played by psychosocial factors in diabetes outcomes, revealed that only 39\% of patients with type 2 diabetes self-reported at least two-thirds success in their self care domains, with adherence being low for diet (37\%) (Peyrot et al., 2005). Additional studies using self-report to assess dietary adherence report suboptimal adherence rates at approximately 70\% or less (Jorgensen, Pollvka, \& Lennie, 2002; Vijan et al., 2004; Rubin, Peyrot, \& Siminerio, 2006; Nelson, McFarland, \& Reiber, 2007).

\section{Exercise}

The importance of exercise for the person with type 2 diabetes cannot be understated. Research has shown that exercise has positive effects on glycemic control (Kavookjian et al., 2007), and can lower the risk of type 2 diabetes (Jeon et al., 2007). However, of all the areas of self-management, adherence to exercise recommendations appears to be most challenging, with adherence rates being lowest for this component of self-management. Long-term adherence to exercise plans for the person with diabetes is poor (Wing et al., 2001). In a nationally representative sample of 2056 patients with diabetes, only $41 \%$ either "always” or "usually” followed their recommended exercise plan (Ruggiero et al., 1997). Results from the DAWN study revealed that out of the selfmanagement domains measured, adherence was lowest for exercise (35\%) (Peyrot et al., 2005). Similar results were found in a study of 717 patients with type 2 diabetes where 
self-reported physical activity was low with only $28 \%$ reporting moderate or vigorous physical activity (Nelson et al., 2007). In addition to self-reported low adherence to exercise plans, study drop out rates have also been used as an indicator of low exercise adherence. In a study examining the association between adherence to exercise and the incidence of cardiovascular disease in patients with type 2 diabetes, $37.3 \%$ of patients who had received a home-based exercise plan dropped out of the study, stating reasons of orthopedic problems, lack of time to exercise, and feeling unable to exercise (Shinji, Shigeru, Ryusei, Mitsuru, \& Shigehiro, 2007).

\section{Medication Taking}

Although diet and exercise are considered the cornerstone of treatment for type 2 diabetes (ADA, 2008), the addition of oral hypoglycemic agents (OHA) is often necessary for maintaining glycemic control. Adherence with medication is strongly associated with glycemic control. Intensive therapy to maintain glycemic control has been associated with a $0.9 \%$ decrease in HbA1c level $(7.0 \%$ versus $7.9 \%$ in a control group receiving conventional diet therapy alone; $\mathrm{p}<.0001$ ) (Turner, Cull, Frighi, \& Holman, 1999). In a study assessing the influence of medication adherence on HbA1c levels in 1560 patients with type 2 diabetes, adherence rates of greater than $76 \%$ were associated with lower HbA1c levels (Rhee et al., 2005). In a study of 810 type 2 diabetes patients from an indigent population, each 10\% increment in drug adherence reduced HbA1c level by $0.16 \%$ (Schectman, Nadkarni, \& Voss, 2002).

Evaluating adherence to medication taking by the person with diabetes presents with many challenges. In a systematic review of 20 studies with quantitative data on adherence, rates of adherence with oral hypoglycemic agents (OHA) ranged from 36\% to 
93\%, depending on the types and numbers of OHA being used and the types of patients being studied (Cramer, 2004). Potential reasons for this wide range include factors such as disease beliefs, concomitant disease states, social support needs, age, and complexity of treatment (Bartels, 2004).

Complexity of Treatment

Patients with type 2 diabetes typically start by taking one oral hypoglycemic agent (OHA), often referred to as mono-therapy. However, given the progressive nature of type 2 diabetes, it is common for patients over time to require additional OHA, referred to as combination therapy (Turner et al., 1999; Bartels, 2004). Research indicates that adherence rates are typically better if the OHA regimen is kept simple, with monotherapy typically having better adherence rates than combination therapy (Cramer, 2004). In a retrospective database analysis of a national pharmacy benefit manager organization, 992 patients with type 2 diabetes were examined to determine the impact of regimen complexity on adherence to OHA. Dosing frequency was found to affect adherence, such that once-daily dosing showed $60.5 \%$ adherence, whereas twice a day dosing showed 52\% adherence (Dezii, Kawabata, \& Tran, 2002). Similar findings occurred in a sample of 2920 Scottish subjects with type 2 diabetes. Only one in three patients had adequate adherence to OHA ( $\geq 90 \%$ ), with significant linear trends of poorer adherence with each increase in the daily number of tablets taken (Donnan et al., 2002). The effects of regimen complexity also changes over time. In a study comparing the use of OHA in newly-treated and previously-treated patients, no significant differences were found in adherence rates $(\mathrm{N}=6502)$ in those newly-treated patients receiving mono-therapy or combination therapy. However, in previously treated patients $(\mathrm{N}=1815)$, lower 
adherence rates were found in the patients receiving combination therapy (54\%)

compared to switched to fixed-dose combination therapy (77\%) (Melikian, White, Vanderplas, Dezii, \& Chang, 2002).

Pharmacy Refill Adherence.

Retrospective analysis of electronic pharmacy databases has provided a substantial body of adherence research. Refill adherence, a calculation based on the number of days of drug therapy dispensed divided by the number of days between the first and last refill, has been used as an objective measure of adherence with large datasets of persons with diabetes. Studies with sample sizes of $N=3358, N=85,888$, and $\mathrm{N}=11,532$ revealed overall adherence rates with OHA at $86 \%, 79 \%$, and $54.8 \%$ respectively (Morningstar, Sketris, Kephart, \& Sclar, 2002; Boccuzzi et al., 2001; Ho et al., 2006). In a study looking specifically at a rural-indigent population, pharmacy records of 1984 patients showed that refill adherence was less than $80 \%$ for one third of the population (Schectman, Bovbjerg, \& Voss, 2002). Within adherence studies, regression analyses identified length of prescription, age, race, gender, comorbidity, and number of medications to be taken as significant independent predictors of pharmacy refill adherence (Sclar et al., 1999; Schectman, Bovbjerg, \& Voss, 2002; Schectman, Nadkarni, and Voss, 2002; Ho et al, 2006).

\section{Conclusion}

In asking the question, 'Why study the relationship between cognitive appraisal of perceived threat of illness and treatment adherence?' several suggestions can be offered. First, studying cognitive appraisal of perceived threat can examine both the primary and secondary appraisals an individual makes in response to perceived threat of illness. In 
addition to gaining knowledge about health behavior, measuring both primary and secondary appraisals may also provide opportunities to screen for diabetics at risk for non-adherence by identifying inaccurate primary appraisals (for example, underestimating the threat of an illness or behavior), and secondary appraisals that may be suboptimal (for example, ineffective coping resources, such as denial, in response to primary appraisal of threat of illness). Second, although primary appraisal of perceived threat of illness has been studied and measured in the research on treatment adherence, there is a lack of measurement of secondary appraisal. Understanding secondary appraisals when experiencing perceived threat of illness may provide more knowledge about the rationales and decisions individuals make in regards to treatment adherence. Secondary appraisals are critical when there is a primary appraisal of harm, loss, threat or challenge (Folkman, 1984). The individual determines which coping options are available, such as changing the situation, trying to unwind and put things into perspective, or possibly expressing feelings and frustrations. Both primary and secondary appraisals are necessary because whether or not a situation is threatening is also influenced by evaluation of one’s coping resources (Folkman \& Lazarus, 1985). And finally, consistent with the ideology of adherence, understanding how an individual appraises the perceived threat of illness may facilitate the patient-healthcare provider relationship by providing insight into patient decision-making regarding treatment adherence. 


\section{CHAPTER 3: METHODOLOGY}

The purpose of this exploratory, descriptive study was to examine cognitive appraisal of perceived threat of diabetes in relation to adherence to recommended selfmanagement behaviors in uninsured persons with type 2 diabetes. The research question asked was "What is the relationship between cognitive appraisal of perceived threat of diabetes and adherence to recommended self-management behaviors of uninsured diabetic patients?” Specifically, the aims of this study were:

1. To describe the cognitive appraisal of perceived threat of diabetes in uninsured persons with diabetes.

2. To describe the levels of diabetes self-management behaviors, including diet, exercise, and medication taking in uninsured persons with diabetes.

3. To describe levels of hemoglobin A1c in uninsured persons with diabetes.

4. To analyze the relationship between the cognitive appraisal of perceived threat of diabetes and self-management behaviors of diet, exercise, and medication taking in uninsured persons with diabetes.

5. To analyze the relationship between cognitive appraisal of perceived threat of diabetes and hemoglobin A1c levels, controlling for the self-management behaviors of diet, exercise, and medication taking in uninsured persons with diabetes.

\section{Sample}

The convenience sample for this exploratory, descriptive study was composed of participants recruited from a free clinic in West Virginia. The inclusion criteria were: 1) age $\geq 18$ years, 2) diagnosis of type 2 diabetes, 3) the ability to read, write, and understand English, 4) uninsured and receiving care at a free clinic. The literature 
provides mixed findings regarding the duration of diabetes and its association with selfmanagement behaviors and diabetes control (Krapek et al., 2004; Rhee et al., 2005; Hartz et al., 2006; Mateo, Gil-Guillen, Mateo, Orozco, \& Carbayo, 2006). For this reason, all persons with diabetes meeting the above inclusion criteria were included in the study. This study was approved by the Institutional Review Board of West Virginia University.

\section{Variable Definitions}

\section{Cognitive Appraisal \\ Conceptual definition.}

Cognitive appraisal refers to the process that an individual uses to constantly evaluate what is happening to them from the standpoint of its significance for their well being (Lazarus and Folkman, 1987). There are two major forms of appraisal: (a) primary appraisal, and (b) secondary appraisal. Primary and secondary appraisals come together to determine the meaning an individual places on an encounter. Both primary and secondary appraisals are necessary because whether or not a situation is threatening is also influenced by evaluation of one’s coping resources (Folkman \& Lazarus, 1985).

\section{Operational Definition.}

Cognitive appraisal of perceived threat of diabetes was measured with the Cognitive Appraisal of Health Scale (Kessler, 1998). The Cognitive Appraisal of Health Scale (CAHS) was designed to measure the dimensions of primary and secondary appraisal associated with health-related events. Secondary appraisal scales include items measuring coping options and resources. Based on the transactional model of stress and coping, the premise of this instrument is that an individual could appraise a potentially stressful event in multiple ways. It was also designed with the knowledge that few 
researchers have measured both primary and secondary appraisal at the same time. The scale consists of 28 items that are scored on a 5-point Likert scale ranging from 1 (strongly disagree) to 5 (strongly agree). Four subscales assess the primary appraisal components of threat, challenge, harm/loss, and benign/irrelevant. Each of the subscales is calculated to provide a unique score for each primary appraisal item. Five discrete items are used to measure secondary appraisal. Subjects are asked to respond to each items based on their cognitive appraisal of their current health condition. Higher scores on each scale item indicate greater agreement with that appraisal item.

Initial support for reliability and validity testing for this instrument was gathered in a study of 201 women with breast cancer. A factor analysis of the 28 items produced a four-factor solution that explained $60 \%$ of the total variance and represented the primary appraisal dimension. Correlations between primary and secondary appraisals were consistent with theoretical predictions $(\mathrm{p}<.01)$ as described by Lazarus and Folkman (1984). Internal consistency estimates of the primary appraisal scale were all greater than .70 .

The CAHS has been studied in patients with prostate cancer (Ahmad, 2005; Ahmad, Musil, Zauszniewski, \& Resnick, 2005). Additional psychometric testing using confirmatory factor analysis produced a three-factor model that accounted for $55.48 \%$ of the variance and represented three of the four original primary appraisal dimensions (Ahmad, 2005). The three factors kept in this model were threat, harm/loss, and challenge. This reduced the instrument to a 13-item instrument. Internal consistency for the total scale produced a Cronbach's alpha of .70. Internal validity was confirmed by 
principal factor analysis. Construct validity was confirmed through structural equation modeling.

For this study, the original 28-item was used. The CAHS was pilot tested for readability in a sample population of patients visiting the free clinic from where the study sample was drawn. Pilot testing indicated that the tool was readable and understandable to the sample population of interest (Carpenter, 2007, unpublished). The SMOG level for this instrument was calculated at the "some high school" or 8.86 grade level (National Literacy Trust, 2007). Subjects were given the choice of either reading the questionnaire themselves, or having it read to them (Appendix A).

\section{Adherence}

Conceptual definition.

For this study, adherence was defined as the management of the daily regimen tasks an individual performs to manage diabetes, and included the management of lifestyle behaviors of diet, exercise, and medication management.

\section{Operational definition.}

For this study, adherence to treatment was operationally defined by measuring self-reported self-management behaviors for diet, exercise, and medication taking using the Summary of Diabetes Self-Care Activities Measure (Toobert \& Glasgow, 1994). Additionally, the objective measure of HbA1c was collected from the patient medical record.

The summary of diabetes self-care activities measure (SDSCA).

The use of self-report measures is very common in adherence research due to its practicality and cost-effectiveness (Toobert, Hampson, \& Glasgow, 2000). Although self 
report is often considered to be unreliable, many researchers have developed and used self report measures that have demonstrated adequate reliability and validity.

The SDSCA is a brief self-report instrument measuring levels of self-management of seven aspects of a diabetes regimen, including diet, exercise, and medication. The tool measures each component as opposed to providing a cumulative score due to the multidimensional nature of self-management. The SDSCA measures self-management as opposed to adherence due to the lack of an unchanging standard against which behavior should be compared. Its use in adults with type 2 diabetes is well established (Tu \& Morrison, 1996; Schectman, Nadkarni, \& Voss, 2002; Ciechanowski et al., 2004; Sarkar, Fisher, \& Schillinger, 2006; Delahanty et al., 2007. Average inter-factor correlations ranged from .16 to .21, and average inter-item correlations within each subscale exceeded .50. Initial validity testing with principal component factor analyses to evaluate factor patterns showed that all items loaded highly on their intended underlying factor. Additionally, test-retest reliability coefficients suggested modest degree of self-care behavior consistency ranging from .43 to .58 (Toobert \& Glasgow, 1994).

For this study, the subscales for diet, exercise, and medication taking were used. For each of these scales, the subject is asked about these specific diabetes self-care activities over the past seven days. The number of days per week uses a scale of 0 to 7 . Two items measure general diet, two items measure specific diet, two items measure exercise, and three items measure medication taking (one item for general medication taking, and two items if insulin is included in the medication regimen). The SMOG level for this instrument was calculated at the "some high school" or 10.75 grade level 
(National Literacy Trust, 2007). The subject was given the choice of either reading the questionnaire themselves, or having it read to them (Appendix B).

\section{$\underline{\text { Hemoglobin A1c. }}$}

The patients included in this study had hemoglobin A1c levels drawn as part of their routine diabetes care. The measurement of hemoglobin A1c (HbA1c) was done by two separate outside laboratories. The HbA1c blood sample was drawn by a clinician in the free clinic then sent to either one of two outside local hospital laboratories for analysis. One laboratory used the Dade Dimension technique, using the turbidimetric inhibition immunoassay principle, where the total hemoglobin is based on a modification of the alkaline hematin reaction (McMillan, 2007). The percentage of total hemoglobin that is glycated is calculated and reported as \%HbA1c. The reference range is 4.8 to 6.0\%. The other laboratory performed HbA1c testing using the BioRad Variant II system, which used ion exchange high-performance liquid chromatography (HPLC) to determine percentage of glycated hemoglobin (Hinkle, 2007). The reference range is 4.4\% to $6.8 \%$. The most recent HbA1c measure prior to entry into the study was used in this analysis.

\section{Demographic Characteristics}

Demographic data collected included: age, duration of diabetes, ethnicity, gender, marital status, education, and co-morbidities. Operationally, these data were defined as follows:

Age

Age was collected by self-report, and recorded in years. 
Gender

Gender was collected by self-report, and recorded as either male or female.

\section{Duration of diabetes}

Duration of diabetes was collected by using patient self report. Subjects were asked to report the number of years that they have had diabetes. Self-report of duration of disease has been used frequently in research, and typically reported in blocks of years (ie. $<5$ years, $5-10$ years, $>10$ years).

\section{Ethnicity}

Ethnicity was collected by self-report. Ethnicity was recorded in the following categories: white, African-American, Asian, Hispanic, Native American, and other.

\section{Marital status}

Marital status was collected by self-report. Marital status was recorded in the following categories: single, married, divorced, separated, widowed, significant other.

\section{Education}

Education was collected by self-report. Education was recorded in the following categories: < high school, graduated high school, some college, college graduate, master's degree, doctorate, GED.

\section{Co-morbidities}

Co-morbidities were collected by using patient self report. Subjects were asked to self- report their co-morbidities. The number of co-morbidities was then summed, and the total number recorded for data analysis. 
Procedure

After receiving permission to conduct the study from the West Virginia University Institutional Review Board, staff of the free clinic was provided with information about inclusion criteria to assist with identifying subjects who may be interested in participation. Subjects were approached by the investigator (or designee) at a regularly scheduled office visits, and the study was described. After obtaining permission from the subject, the investigator (or designee) administered three selfcompletion questionnaires, or gave the subject the choice of reading the questionnaires themselves: the SDSCA, the CAHS, and the Subject Health History form (Appendix C). The estimated time to complete the surveys was approximately 10 to 15 minutes. Following completion of these questionnaires, the most recent HbA1c value and the time since that last HbA1c value were collected from the medical record by the investigator (or designee).

To maintain confidentiality, no information identifying the subject was on the surveys. All completed surveys were kept in a secured drawer in the clinic. All data were then transported from the clinic to the investigator's office by the investigator. All data were analyzed using the Statistical Package for Social Sciences (SPSS), version 15, computer software program (SPSS, 2006). All data were entered into SPSS by the researcher only. All data were kept in secured file in a locked office by the investigator. 


\section{CHAPTER 4: RESULTS}

Prior to analysis, data were cleaned, looking for outliers or impossible values. This was accomplished by running frequencies and descriptive statistics and visually scanning for missing data and for patterns of missing data. No variable had greater than 3\% missing data, and missing data were random without any identifiable pattern. All subjects were included in this analysis. Pairwise exclusion of cases was used in analyses. Sample

The convenience sample for this study was composed of 80 subjects being treated for type 2 diabetes mellitus at a free clinic in West Virginia between January 2008 and May 2008. Sample size estimates were calculated based on Cohen’s technique for power analysis for multiple regression, based on an alpha of .05 and a medium effect size of .80, and 12 independent variables (Cohen, 1988). Based of this calculation, a sample size of 80 subjects was required for analysis. Characteristics of the study sample included a mean age of 50.4 years (range 23 to 64 years), with $27.4 \%$ men and $72.4 \%$ women. The majority of subjects were white (94.7\%), had diabetes for less than 10 years (82.9\%), and reported having one to two co-morbidities. Approximately half the subjects were married or had a significant other (53.9\%), and had a high school or GED education (47.4\%). The study sample was compared to the general clinic population and the state of West Virginia in terms of gender (general clinic population: men $=36.7 \%$, women $=$ 63.3\%; West Virginia: men $=48.6 \%$, women $=51.4 \%$ ) and ethnicity $($ general clinic population: white $=91.6 \%$, black $=5.0 \%$; West Virginia: white $=95.9 \%$, black $=3.5 \%$ ) (Zinn, 2008). The study sample was representative of the general clinic on these variables (See Table 1). 
Table 1: Sample demographics

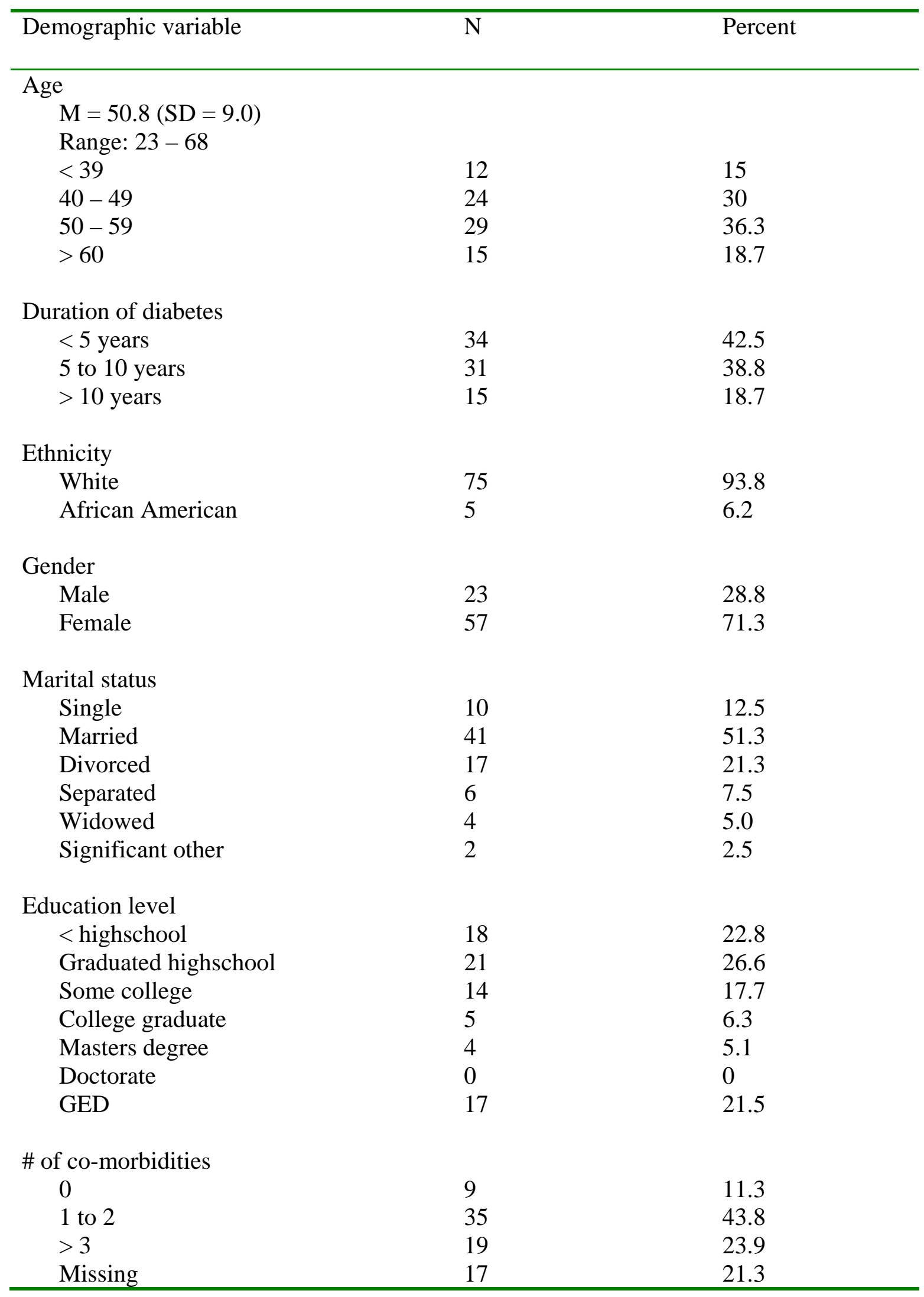


Factor Analysis: Cognitive Appraisal of Health Scale (CAHS)

Prior to analysis of data, a factor analysis of the 19 items from the threat, harm/loss, and challenge subscales from the original CAHS was performed, forcing a 3factor model. Consistent with Lazarus and Folkman (1984), the benign/irrelevant subscale was deleted. This process produced a 3-factor model closely related to the original factors: (a) Factor 1 = threat (with some loss items that can be interpreted as threat items), (b) Factor 2 = harm/loss (with two control and two harm/loss items), and (c) Factor 3 = challenge. The Kaiser-Meyer-Oklin (KMO) for this 3-factor model is .76 (KMO $>0.6$ is acceptable), and Bartlett's Test of Sphericity was significant $(\mathrm{p}<.001)$ (Tabachnick \& Fidell, 2001). See Table 2 for a summary of the factor analysis. 
Table 2: Factor analysis of the items of the CAHS

Items

Factor analysis with Varimax rotation

Factor $1 \quad$ Factor $2 \quad$ Factor 3

A1. I can control what will happen to me.

A2. Diabetes won't get me down.

$\dagger$

A3. I have not been able to do what I want

$-.414$ to do because of having diabetes.

A4. Diabetes is frightening to me.

.604

.744

A6. Things will only get worse because of

.687 having diabetes.

A7. My diabetes will not go well. 372

A8. Having diabetes has damaged my life. $\quad \mathbf{. 7 3 4}$

A9. I have lost interest in the things around $\mathbf{. 5 0 3}$ me.

A10. I have had to give up a great deal $\quad .755$ because of having diabetes.

A11. I can beat diabetes despite the difficulties.

A13. I have a sense of loss over the things I $\quad \mathbf{. 7 2 5}$ can no longer do.

A14. I feel I can handle having diabetes. †

A17. I have a lot to lose because of having

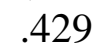
diabetes.

A18. I worry about what will happen to me.

.515

A19. Relationships with my family and .514 friends have suffered.

$-.309$

$-.699$

$-.361$

$\dagger$

$\dagger$

$+$

$\dagger$

$\dagger+$

$\dagger \quad-.391$

A21. I have been harmed in some way by my $\quad \dagger$ having diabetes.

A24. This health condition has caused me to $†$ learn more about myself.

A25. I have been hurt by my diabetes.

A26. There is a lot I can do to overcome my diabetes.

$\dagger+$

$\dagger$

$\dagger$

$\dagger$

$\dagger \quad+$

$-.696$

$\begin{array}{ll}.719 & \dagger \\ \dagger & .711\end{array}$




\section{Specific Aims}

Aim 1: To describe the cognitive appraisal of perceived threat of diabetes in uninsured persons with diabetes.

To describe the appraisal of perceived threat of illness in the study sample, the means, standard deviations, and ranges for each of the appraisal variables on the Cognitive Appraisal of Health Scale were analyzed (See Table 3). Correlations between primary and secondary appraisal variables support the theoretical assertions of the CAHS. Correlations between appraisal variables are presented in Table 4.

Table 3: Appraisal variables

\begin{tabular}{lllll}
\hline Variable & Mean & SD & $\begin{array}{l}\text { Study } \\
\text { Range }\end{array}$ & $\begin{array}{l}\text { Scale } \\
\text { Range }\end{array}$ \\
\hline $\begin{array}{l}\text { Threat appraisal scale } \\
\quad \text { primary appraisal) }\end{array}$ & 14.3 & 4.1 & $5-22$ & $5-25$ \\
$\begin{array}{c}\text { Challenge appraisal scale } \\
\quad \text { (primary appraisal) }\end{array}$ & 22.8 & 3.5 & $11-29$ & $6-30$ \\
$\begin{array}{c}\text { Harm or loss appraisal scale } \\
\quad \text { (primary appraisal) }\end{array}$ & 19.6 & 6.1 & $8-37$ & $8-40$ \\
$\begin{array}{c}\text { Can change [item 12] } \\
\quad \text { (secondary appraisal) }\end{array}$ & 3.70 & 1.10 & $1-5$ & $1-5$ \\
$\begin{array}{c}\text { Hold back [item 16] } \\
\quad \text { (secondary appraisal) }\end{array}$ & 2.28 & 1.06 & $1-5$ & $1-5$ \\
$\begin{array}{c}\text { Nothing to do [item 20] } \\
\text { (secondary appraisal) }\end{array}$ & 1.79 & .97 & $1-5$ & $1-5$ \\
$\begin{array}{c}\text { Need to know more [item 22] } \\
\text { (secondary appraisal) }\end{array}$ & 2.54 & 1.18 & $1-5$ & $1-5$ \\
$\begin{array}{l}\text { Have to accept [item 27] } \\
\quad \text { (secondary appraisal }\end{array}$ & 4.13 & .84 & $1-5$ & $1-5$ \\
\hline
\end{tabular}

Subscale alphas: Threat $=.69 ;$ Harm/loss $=.82$; and Challenge $=.68$ 
Table 4: Correlations between primary and secondary appraisal variables

\begin{tabular}{lccc}
\hline Subscale & Threat & Harm/loss & Challenge \\
\hline $\begin{array}{l}\text { A12: Having diabetes is something I } \\
\text { can change or do something about }\end{array}$ & $-.288^{* *}$ & $-.318^{* *}$ & $.492^{* *}$ \\
$\begin{array}{l}\text { A16: Because of diabetes, I have to } \\
\text { hold myself back from doing what I want }\end{array}$ & $.588^{* *}$ & $.646^{* *}$ & $-.332^{* *}$ \\
$\begin{array}{l}\text { A20: There is nothing I need to do } \\
\text { for my diabetes }\end{array}$ & .196 & $.275^{*}$ & -.213 \\
$\begin{array}{l}\text { A22: I need to know more before I } \\
\text { can do anything about my diabetes }\end{array}$ & $.375^{* *}$ & $.413^{* *}$ & $-.310^{* *}$ \\
$\begin{array}{l}\text { A27: I have to accept my diabetes } \\
* * \mathrm{p}<.01 \quad * 05\end{array}$ & & \\
\end{tabular}

Aim 2: To describe the levels of diabetes self-management behaviors, including diet, exercise, and medication taking in uninsured persons with diabetes.

Level of adherence to diabetes self-management behaviors was measured with subscales of the Summary of Diabetes Self Care Activities (SDSCA) scale. Based on days per week, the sample followed recommendations for taking prescribed oral medications an average of 6.6 days, for general diet an average of 4.1 days, for specific diet 3.7 days, and for exercise an average of 2.9 days. The mean and standard deviation of diabetes self-management behaviors for the study sample are presented in Table 5.

Table 5: Diabetes self-management behaviors

\begin{tabular}{lccc}
\hline Variables & $\mathrm{N}$ & Mean \# days/week & $\mathrm{SD}$ \\
\hline General diet & 80 & 4.07 & 1.84 \\
Specific diet & 78 & 3.83 & 1.54 \\
Exercise & 80 & 2.85 & 2.12 \\
Oral medication taking & 78 & 6.64 & 1.29 \\
\hline
\end{tabular}


Aim 3: To describe levels of hemoglobin A1c in uninsured persons with diabetes.

The mean, standard deviation, and range of the most recent HbA1c values as well as the length of time since last HbA1c value for each subject prior to entry into the study are presented in Table 6. Out of 79 patients, 38 patients (49.4\%) had HbA1c levels of 7\% or greater. One subject refused to have blood drawn, and 21 subjects reported no prior HbA1c level being drawn at this clinic.

Table 6: HbA1c level and time since last level

\begin{tabular}{lllll}
\hline Variable & $\mathrm{N}$ & Mean & SD & Range \\
\hline Hemoglobin A1c level & 79 & 7.56 & 1.90 & $5.50-14.30$ \\
Time (days) since last level & 58 & 153.74 & 85.79 & $4-420$ \\
& & $(5.1$ months $)$ & & $(0-14$ months $)$ \\
\hline
\end{tabular}

Aim 4: To analyze the relationship between the cognitive appraisal of perceived threat of diabetes and self-management behaviors of diet, exercise, and medication taking in uninsured persons with diabetes.

Separate but parallel regression models were created to address this aim. Prior to running regression models, correlations were run between the appraisal variables and the self-management variables. Correlations were run to determine the direction of significant relationships between cognitive appraisal variables and self-management variables. Several significant relationships were found between appraisal variables and self-management variables. Findings show a significant negative association between threat and general diet, such that as the perception of diabetes as a threat decreases, days of adherence to general diet increases. A significant negative association was also found 
between coping options and both general and specific diet, such that as the perception that there is "nothing to do for diabetes" decreases, days of adherence to general and specific diet increases. Findings also show a significant positive association between challenge and general diet, such that as the perception of diabetes as a challenge increases, days of adherence to general diet increases. A significant positive association was also found between the coping option of "having to accept diabetes" and general diet, such that as the perception that diabetes was something that had to be accepted increased, days of adherence to general diet increased. Results are found in Table 7 and 8.

Prior to interpreting multiple regression models, tests for the assumptions of multivariate regression were performed. To test linearity, scatterplots for each independent variable on the dependent variable were evaluated. To test normality, Q-Q plots of the unstandardized residuals for each model were evaluated. To test homoscedasticity (homogeneity of variance), scatterplots of standardized residuals and the standardized predicted values (part of the SPSS Collinearity diagnostics program) were evaluated for each regression model. To test for the absence of multicollinearity, tolerance and VIF values were evaluated.

Collinearity diagnostics produced tolerance values ranging from .27 to .83 , and VIF values $<3.7$, suggesting the absence of multicollinearity. Outliers were assessed by inspecting Mahalanobios’ distances. The critical value for Mahalanobois’ distance for 12 independent variables is 32.9 (Tabachnick \& Fidell, 2001). The range for this regression was 2.6 to 28.8, indicating no outliers. Q-Q plots to test for normality (Appendix D) demonstrated that percentiles of the sample data look similar to data from a normal 
distribution with the same mean and standard deviation. From this it can be assumed that the error terms of the sample data come from a normal population. Tests for linearity demonstrated that no non-linear relationships exist between the independent variables and the dependent variable. The scatterplot of residuals versus predicted values from the 
Table 7: Correlations between primary appraisal and self-management behavior variables

\begin{tabular}{|c|c|c|c|c|c|c|c|}
\hline & $\begin{array}{l}\text { Oral } \\
\text { medication }\end{array}$ & General diet & Specific diet & Exercise & Threat & Challenge & Harm/loss \\
\hline $\begin{array}{l}\text { Oral } \\
\text { medication }\end{array}$ & 1.00 & .167 & .012 & .032 & .099 & .072 & .109 \\
\hline General diet & & 1.00 & $.337 * *$ & $.313 * *$ & $-.311 * *$ & $.354 * *$ & -.176 \\
\hline Specific diet & & & 1.00 & .210 & -.180 & .116 & -.186 \\
\hline Exercise & & & & 1.00 & -.183 & .147 & -.122 \\
\hline Threat & & & & & 1.00 & $-.476 * *$ & $.728 * *$ \\
\hline Challenge & & & & & & 1.00 & $-.558 * *$ \\
\hline Harm/loss & & & & & & & 1.00 \\
\hline
\end{tabular}

** Correlation is significant at the 0.01 level 
Table 8: Correlations between secondary appraisal and self-management behavior variables

\begin{tabular}{|c|c|c|c|c|c|c|c|c|c|}
\hline & $\begin{array}{c}\text { Oral } \\
\text { medication }\end{array}$ & $\begin{array}{c}\text { General } \\
\text { diet }\end{array}$ & $\begin{array}{c}\text { Specific } \\
\text { diet }\end{array}$ & Exercise & $\begin{array}{c}\text { Can } \\
\text { change }\end{array}$ & Hold back & $\begin{array}{c}\text { Nothing to } \\
\text { do }\end{array}$ & $\begin{array}{c}\text { Need to } \\
\text { know } \\
\text { more }\end{array}$ & $\begin{array}{c}\text { Have to } \\
\text { accept }\end{array}$ \\
\hline $\begin{array}{l}\text { Oral } \\
\text { medication }\end{array}$ & 1.00 & .167 & .012 & .032 & .108 & .080 & .023 & -.156 & .135 \\
\hline General diet & & 1.00 & $.337 * *$ & $.313^{* *}$ & .211 & -.186 & $-.232 *$ & -.121 & $.240^{*}$ \\
\hline Specific diet & & & 1.00 & .210 & -.110 & -.197 & $-.243 *$ & -.001 & .002 \\
\hline Exercise & & & & 1.00 & .032 & -.069 & .052 & .131 & .001 \\
\hline Can change & & & & & 1.00 & -.080 & -.206 & -.140 & -.018 \\
\hline Hold back & & & & & & 1.00 & $.283 *$ & $.269 *$ & -.143 \\
\hline $\begin{array}{l}\text { Nothing to } \\
\text { do }\end{array}$ & & & & & & & 1.00 & .182 & $-.248^{*}$ \\
\hline $\begin{array}{l}\text { Need to } \\
\text { know more }\end{array}$ & & & & & & & & 1.00 & $-.276^{*}$ \\
\hline $\begin{array}{l}\text { Have to } \\
\text { accept }\end{array}$ & & & & & & & & & 1.00 \\
\hline
\end{tabular}


SPSS diagnostics shows a random scatter of points inside a horizontal band about zero, supporting homoscasdicity of the sample data (Appendix E).

The following criteria were used in evaluating all regression models: (a) the adjusted $R^{2}$ value was used for interpreting the amount of variance explained by the variables in each model. For smaller sample sizes, the $R^{2}$ can overestimate the true value in the population (Tabachnick \& Fidell, 2001). Because the sample size of this study was $\mathrm{N}=80$, the adjusted $R^{2}$ value was more appropriate to use. (b) the unstandardized coefficient (B) was used in determining the unique contribution of each variable in each model. The unstandardized coefficient is appropriate to use when the independent variables are measured on scales that are not equal. In this study, the threat subscale $(\mathrm{R}=$ 5-25), challenge subscale $(\mathrm{R}=6-30)$, and harm/loss subscale $(\mathrm{R}=8-40)$ were not equal in scale, thus the unstandardized coefficient (B) was used. When using the unstandardized coefficient (B), it is the significance level that determines the order of strength of each independent variable in explaining the dependent variable.

\section{Model for General Diet}

Multiple linear regression was employed to help determine which of the cognitive appraisal variables and demographic variables could be used to predict the levels of adherence to general diet. A direct enter method was used for the multiple linear regression analyses.

Correlations among the 12 independent variables were examined and ranged from small to moderate with the exception of the harm/loss and threat. Harm/loss and threat correlated at .728; however, both variables were kept in the analysis because of theoretical meanings underlying each of the subscales. Correlations between the 
independent variables and the dependent variable of general diet were small to moderate, ranging from .002 to .35 , indicating that the data were suitably correlated with the dependent variable for examination through multiple linear regression.

The cognitive appraisal variables and the demographic variables of age, gender, duration of diabetes, and marital status produced an $R^{2}$ of .28 $(F(12,60)=1.97, p=.04)$ for the prediction of general diet. The adjusted $R^{2}$ for this model was .14. The three primary appraisal variables of threat, challenge, and harm/loss made significant contributions to the model. The strongest predictor was threat $(\mathrm{p}=.02)$, with a part correlation of -.26, thus uniquely explaining $7 \%$ of the variance in general diet. Second was harm/loss $(\mathrm{p}=.045)$, with a part correlation of .22, thus uniquely explaining $5 \%$ of the variance in general diet. The third independent variable was challenge $(p=.05)$, with a part correlation of .22, thus uniquely explaining $5 \%$ of the variance in general diet.

Findings show a significant negative association between threat and general diet, such that as the perception of diabetes as a threat decreased, days of adherence to general diet increased. Findings also showed a significant positive association between harm/loss and challenge appraisals and general diet, such that as the perception of diabetes causing harm/loss and being a challenge increased, days of adherence to general diet increased (Table 9). 
Table 9: Multiple regression analysis for general diet

Summary of Standard Multiple Regression Analysis for Variables Predicting Adherence Levels to General Diet in Persons with Type 2 Diabetes $(N=72)$

\begin{tabular}{|c|c|c|c|c|}
\hline Variable & B * & beta ** & $p$ & Part \\
\hline Threat (primary appraisal) & -190 & -.421 & .020 & $-.26(7 \%)$ \\
\hline Harm/loss(primary appraisal) & .129 & .429 & 045 & $.22(5 \%)$ \\
\hline Challenge (primary appraisal) & 162 & 306 & .050 & $.22(5 \%)$ \\
\hline Gender & 831 & 206 & .107 & \\
\hline Nothing I need to do & -.290 & -.153 & 220 & \\
\hline Marital status & -.384 & .085 & .059 & \\
\hline I have to accept & .183 & .083 & .519 & \\
\hline Age & .011 & .056 & 673 & \\
\hline Hold back from doing what I want & -.106 & -.061 & 697 & \\
\hline I need to know more & .079 & .051 & 698 & \\
\hline Can change or do something about & .055 & .033 & .808 & \\
\hline Duration of diabetes & -.017 & -.007 & .957 & \\
\hline
\end{tabular}

$R^{2}=.28$, adjusted $R^{2}=.14, F=1.97, p=.04$;

* Unstandardized beta; ** Standardized beta

Model for Specific Diet

Multiple linear regression was employed to help determine which of the cognitive appraisal variables and demographic variables could be used to predict the levels of adherence to specific diet. A direct enter method was used for the multiple linear regression analyses. Correlations amongst the 12 independent variables were examined and ranged from small to moderate with the exception of harm/loss and threat. Harm/loss 
and threat correlated at .728; however, both variables were kept in the analysis because of theoretical meanings underlying each of the subscales. Correlations between the independent variables and the dependent variable of specific diet were small to moderate, indicating that the data is suitably correlated with the dependent variable for examination through multiple linear regression.

By removing predictors with the non-significant regression coefficients (the primary appraisal variables, three secondary appraisal variables, marital status, and duration of diabetes), the secondary appraisal variables of "Nothing I need to do" and “Can change or do something about”, and the demographic variables of age and gender made significant contributions to a model that produced $R^{2}$ of .36 $(F(12,60)=2.79, p=$ .004) for the prediction of specific diet. The adjusted $R^{2}$ for this model was .23 . The strongest predictor was "Nothing I need to do $(p=.004)$, with a part correlation of -.31 , thus uniquely explaining $10 \%$ of the variance in specific diet. Second was gender $(\mathrm{p}=$ $.005)$, with a part correlation of .30 , thus uniquely explaining $9 \%$ of the variance in specific diet. Third was age $(p=.006)$, with a part correlation of .30 , thus uniquely explaining $9 \%$ of the variance in specific diet. Fourth was "Can change or do something about” $(p=.028)$, with a part correlation of -.23 , thus uniquely explaining $5 \%$ of the variance in specific diet.

Findings show a significant negative association between coping options (secondary appraisal) and specific diet, such that as perception that "diabetes is something that can be changed", and that "there is nothing needed to do for diabetes" decreased, days adherence to specific diet increased. Findings also showed a significant 
positive association between age and specific diet, such that as age increased, days

adherence to specific diet increased (Table10).

Table 10: Multiple regression analysis for specific diet

Summary of Standard Multiple Regression Analysis for Variables Predicting Adherence Levels to Specific Diet in Persons with Type 2 Diabetes $(N=72)$

\begin{tabular}{|c|c|c|c|c|}
\hline Variable & $\mathrm{B} *$ & Beta ** & $P$ & Part \\
\hline Nothing I need to do & -.552 & -.348 & .004 & $-.31(10 \%)$ \\
\hline Gender & 1.17 & 349 & .005 & $.30(9 \%)$ \\
\hline Age & .061 & 357 & .006 & $.30(9 \%)$ \\
\hline Can change & -.399 & -.284 & .028 & $-.23(5 \%)$ \\
\hline Threat & -.117 & -.310 & .067 & \\
\hline Have to accept & -.408 & -.223 & .072 & \\
\hline Harm/loss & .057 & 229 & .252 & \\
\hline Challenge & .069 & 156 & .284 & \\
\hline I need to know more & .161 & .124 & .318 & \\
\hline Hold back & -.184 & -.127 & .392 & \\
\hline Marital status & -.099 & -.072 & .528 & \\
\hline Duration of diabetes & -.096 & -.047 & .703 & \\
\hline \multicolumn{5}{|c|}{$\begin{array}{l}R^{2}=.36 \text {, adjusted } R^{2}=.23 ; F=2.79, p=.004 \\
*=\text { Unstandardized beta; } * *=\text { Standardized beta }\end{array}$} \\
\hline
\end{tabular}

Multiple linear regression was employed to help determine which of the cognitive appraisal variables and demographic variables could be used to predict the levels of adherence to exercise and adherence to oral medication taking. A direct enter method was used for the multiple linear regression analyses. This analysis along with additional 
testing produced no significant models predicting exercise or oral medication taking. The model for exercise produced an $R^{2}$ of ..14 $(F(12,60)=.84, p=.608)$ [adjusted $R^{2}=-.03$ ] (Table E), and the model for oral medication taking produced an $R^{2}$ of $.13(F(12,60)=$ $.73, p=.715)$ [adjusted $\left.R^{2}=-.05\right]$.

Aim 5: To analyze the relationship between cognitive appraisal of perceived threat of diabetes and hemoglobin A1c levels, controlling for the self-management behaviors of diet, exercise, and medication taking in uninsured persons with diabetes.

\section{$\underline{\text { Model for HbA1c }}$}

Multiple linear regression was employed to help determine which of the cognitive appraisal variables, controlling for the self-management variables, could be used to predict HbA1c levels.

A direct enter method was used for the multiple linear regression analyses. The first attempt produced a non-significant model. Additional testing of a model that included cognitive appraisal variables and demographic variables, while controlling for three self-management variables produced an $R^{2}$ of .27 $(F(11,61)=2.01, p=.04)$ [adjusted $R^{2}=.13$ ]for the prediction of HbA1c. Collinearity diagnostics produced tolerance values ranging from .33 to .92, and VIF values $<3.1$, suggesting the absence of multicollinearity. Outliers were assessed by inspecting Mahalanobios’ distances. The critical value for Mahalanobois’ distance for 11 independent variables is 31.3 (Tabachnick \& Fidell, 2001). The range for this regression was 3.9 to 21.1, indicating no outliers. Q-Q plots to test for normality (Appendix D) demonstrated that percentiles of the sample data look similar to data from a normal distribution with the same mean and standard deviation. From this it can be assumed that the error terms of the sample data 
comes from a normal population. Tests for linearity demonstrated that no non-linear relationships exist between the independent variables and the dependent variable. The scatterplot of residuals versus predicted values from the SPSS diagnostics shows a random scatter of points inside a horizontal band about zero, supporting homoscasdicity of the sample data (Appendix E).

Correlations among the 11 independent variables were examined and ranged from small to moderate with the exception of the harm/loss and threat. Harm/loss and threat correlated at .728; however, both variables were kept in the analysis because of theoretical meanings underlying each of the subscales. Correlations between the independent variables and the dependent variable of HbA1c were small to moderate, indicating that the data is suitably correlated with the dependent variable for examination through multiple linear regression. The strongest predictor of HbA1c was harm/loss $(\mathrm{p}=$ .001 ), with a part correlation of .38, thus uniquely explaining $14 \%$ of the variance in HbA1c. Second was general diet $(\mathrm{p}=.014)$, with a part correlation of .-.28, thus uniquely explaining $8 \%$ of the variance in HbA1c. Third was threat $(\mathrm{p}=.019)$, with a part correlation of -.27 , thus uniquely explaining $7 \%$ of the variance in HbA1c. Fourth was “nothing I need to do" $(\mathrm{p}=.038)$, with a part correlation of -.23 , thus uniquely explaining $5 \%$ of the variance in HbA1c. Fifth was challenge $(\mathrm{p}=.044)$, with a part correlation of .23, thus uniquely explaining $5 \%$ of the variance in HbA1c. .

Findings showed a significant negative association between threat and HbA1c, such that as the perception of diabetes being a threat decreased, HbA1c levels increased. Findings also showed a significant negative association between the coping option (secondary appraisal) of "there is nothing needed to do for diabetes" and HbA1c, such 
that as the perception that "there is nothing needed to do for diabetes" decreased, HbA1c levels increased. Findings also showed a significant positive association between the primary appraisal variables of harm/loss and challenge and HbA1c, such that as the perception of diabetes causing harm/loss and being challenging increased, HbA1c levels increased (Table 11).

Table 11: Multiple regression analysis for HbA1c

Summary of Standard Multiple Regression Analysis for Variables Predicting HbA1c Levels in Type 2 Diabetics $(N=72)$

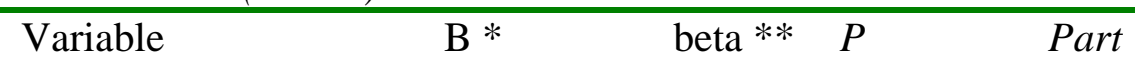

\begin{tabular}{|c|c|c|c|c|}
\hline Harm/loss & .206 & .664 & .001 & $.38(14 \%)$ \\
\hline General diet & -.363 & -.351 & .014 & $-.28(8 \%)$ \\
\hline Threat & -.204 & -.437 & .019 & $-.27(7 \%)$ \\
\hline Nothing I need to do & -.511 & -.260 & .038 & $-.23(5 \%)$ \\
\hline Challenge & .162 & .296 & .044 & $.23(5 \%)$ \\
\hline Duration of diabetes & .400 & .158 & .172 & \\
\hline Need to know more & -.284 & -.176 & .175 & \\
\hline Education & -.139 & -.161 & .177 & \\
\hline Gender & .514 & .123 & .331 & \\
\hline Exercise & .105 & .117 & .352 & \\
\hline Specific diet & .136 & .110 & .391 & \\
\hline
\end{tabular}

$R^{2}=.27$, adjusted $R^{2}=.13, F=2.01, p=.04$

$*=$ Unstandardized beta; $* *=$ Standardized beta 


\section{CHAPTER 5: SUMMARY, DISCUSSION, AND IMPLICATIONS}

It was recognized that a gap in current knowledge exists in terms of understanding diabetes as an event that is appraised by the patient. The purpose of this exploratory, descriptive study was to examine cognitive appraisal of the stress of diabetes in relation to adherence to treatment plan in uninsured persons with type 2 diabetes.

\section{Major Findings}

Adherence to Self-Management Behaviors and HbA1c

The persons with diabetes in this study did well with taking oral medication, but had problems with adherence to dietary and exercise recommendations. Based on days per week, the sample was most adherent with oral medications, and least adherent with diet and exercise. These results are similar with adherence rates that have been reported in other patient populations in the literature (Ruggiero et al., 1997; Wing et al., 2001; Jorgensen et al., 2002; Melikian et al., 2002; Nelson et al., 2005; Cramer, 2004; Murata et al., 2004; Vijan et al., 2004; Peyrot et al., 2005; Rubin et al., 2006; Nelson et al., 2007). It is important to note that the uninsured/underinsured persons with diabetes in this study received their care free of charge. However, the results of this study suggest that being uninsured or underinsured with access to free care does not affect adherence rates to the self-management behaviors of diet, exercise, and oral medication taking. This is in contrast to the literature that supports that the uninsured are less adherent (Tu \& Morrison, 1996; Beckles et al., 1998; Ayanian et al., 2000; Nelson et al., 2005).

Adherence to dietary recommendations has been demonstrated to be problematic. In this study, patients followed dietary recommendations approximately four days per week, or only a little over half of the time recommended. This finding is consistent with 
the current literature on dietary adherence (Jorgensen et al., 2002; Murata et al, 2004;

Vijan et al., 2004; Peyrot et al., 2005; Rubin et al, 2006; Nelson et al, 2007).

Patients in this study followed recommendations for exercise an average of 2.85 days per week. Exercise recommendations for patients seen in this clinic include 30 minutes per day, 3 to 5 days per week. Exercise is one of the most challenging of all the self-management behaviors for persons with diabetes, with adherence rates being lowest for this area of self-management. Literature on exercise adherence has documented adherence rates at 50\% or below (Ruggiero et al, 1997; Shultz, Sprague, Branen, \& Lambeth, 2001; Tuomilehto et al., 2001; Peyrot et al., 2005; Nelson et. al., 2007).

Patients in this study followed recommendations for oral medication taking on average 6.64 days per week, or $95 \%$ of the time. These findings are consistent with much of the literature on adherence rates and oral medications. In terms of days per week, Grant, Devita, Singer, and Meigs (2003) reported adherence rates for oral medications in diabetic patients an average of $6.7 \pm 1.1$ days per week, and found that the number of oral medications prescribed was not correlated to adherence rates. In other studies, adherence rates have been reported of greater than $80 \%$ for medications for diabetes (Walker et al., 2006; Grant et al., 2007; Odegard \& Capocci, 2007; Rozenfeld, Hunt, Plauschinat, \& Wong, 2008).

The mean HbA1c value for this study sample was 7.56 ( $\mathrm{SD}=1.90, \mathrm{R}=5.50$ 14.30), which is consistent with the literature (Krapek et al., 2004; Saydah, Fradkin, \& Cowie, 2004). The recommended HbA1c values for patients treated in the clinic where the sample was drawn is $<7 \%$, following the general guideline set forth by the American Diabetic Association (2008). Additionally, the average time since last drawn HbA1c 
level was 5.1 months (mean $=153.74$ days, $\mathrm{SD}=85.79, \mathrm{R}=4-420)$. Recommended frequency for HbA1c levels is every three months for values > 7\% (ADA, 2008). These results indicate that adherence to recommended HbA1c levels and testing is less than optimal in this study population. Additionally, a total of 22 patients (28\%) reported no previous HbA1c level. One patient specifically refused blood draws, while the remaining 21 reported not having a level drawn before. This finding is also consistent with current literature, where adherence to recommended HbA1c testing ranges from 33\% to 50\% (Saaddine et al., 2002; Resnick, Foster, Bardsley, \& Ratner, 2006; Dailey, 2007; Delaronde, 2007).

Cognitive Appraisal of the Stress of Diabetes

The findings of this study add to the body of knowledge about the role of cognitive appraisal of the stress of diabetes. The patients in this study provided multiple views of the stress of diabetes, with great variability in primary appraisals, including threat, harm/loss, and challenge. Persons with diabetes in this study perceived their diabetes as more of a challenge than as threatening or causing harm or loss. Challenge appraisal refers to a judgment that the demands associated with diabetes can be met or overcome, whereas harm/loss describes damage that has already occurred, and threat refers to anticipated harm/loss from diabetes.

In terms of secondary appraisal, persons with diabetes indicated that diabetes was something that had to be accepted ("have to accept having diabetes”), but at the same time perceived that there was something that needed to be done for their diabetes ("There is nothing I need to do for my diabetes”; $\mathrm{M}=1.79$, indicating low agreement with this 
item), and that diabetes was something that could be changed or acted on ("Having diabetes is something I can change or do something about”; $M=3.7$ ).

Correlations between primary and secondary appraisal variables support the theoretical assertions of the CAHS (Kessler, 1998). Significant correlations were found between the three primary appraisal variables, and four of the secondary appraisal variables. The only secondary appraisal variable that did not correlate with primary appraisal was “having to accept diabetes”.

The results of this study are consistent with findings in other samples with chronic or potentially life-threatening diseases. In exploring cognitive appraisal of the diagnosis of prostate cancer, patients identified threat appraisal with less frequency than appraisals of harm/loss or challenge (Ahmad, 2005). The researchers suggested that high survival rates and longer survival-time for patients with prostate cancer makes living with the disease less threatening and more challenging. Further exploration of this appraisal showed that less harm/loss appraisals were associated with better physical health (Ahmad, et. al., 2005). These results share similarities to other studies of cognitive appraisal of illness situations. In studying cognitive appraisal of a breast cancer diagnosis, Kessler (1998) found that women had multiple views of the stress of a breast cancer diagnosis shown in the mix of harm/loss, threat, and challenge appraisals. It was also observed that threat appraisals were higher in patients with a diagnosis for less than 10 years, and did not change much until after 10 years post-diagnosis. Primary appraisals also influenced coping options (secondary appraisals), such that women who appraised breast cancer as causing harm/loss also reported a greater need to "hold themselves back from doing what they wanted to do" and “to know more before they could act”. 
In exploring cognitive appraisal of melanoma survivors, Hamama-Raz and Solomon (2006), using only the threat, challenge, and select secondary appraisal items, found significant associations between cognitive appraisal and adjustment to illness. Specifically, higher threat perception was associated with less well-being and greater distress; higher challenge perception was associated with greater well-being.

The persons with diabetes in this study may bear some similarities to patients with prostate cancer and melanoma. This similarity in appraisal could be related to how these diseases are perceived. Although the diagnosis of cancer is often viewed as a threat to life, different types of cancer evoke different levels of fear (American Cancer Society, 1996). Prostate cancer has high survival rates and long survival time for patients living with prostate cancer, making this disease less threatening than other types of cancer. The melanoma patients studied were survivors post-treatment with no signs of recurrence. This same thinking can be applied to diabetes, where effective selfmanagement may make diabetes less threatening than other types of illnesses.

\section{Relationship of Cognitive Appraisal and Self-Management Behaviors}

The results of this study do suggest an association between cognitive appraisal and the self-management behaviors related to diet. For persons with diabetes in this study, days adhering to general diet recommendations increased as the perception that diabetes was a threat and was something that required "nothing to do" decreased. Days adhering to general diet recommendation also increased as the perception that diabetes was a challenge and was something that had to be accepted increased.

The results of this study also support the role of cognitive appraisal of the stress of diabetes as a predictor in the adherence to recommended self-management behaviors 
of diet and in the HbA1c level. Examination of the direction of the regression coefficients suggest that as perception of threat decreased and harm/loss and challenge increased, the number of days adhering to general diet increased. For specific diet, secondary appraisal was associated with days adherence such that as appraisals of diabetes being something that could "be changed” and required "nothing to do" decreased, the number of days adhering to specific diet increased. A mix of primary and secondary appraisals were associated with HbA1c level. As perceptions of harm/loss and challenge increased, and threat and perceiving that diabetes required “nothing to do" decreased, HbA1c levels increased. Cognitive appraisal of the stress of diabetes was not explanatory of adherence to oral medication taking and exercise.

Study Findings and the Stress-Response-Sequence Model The major findings of this study show support for the relationships between the concepts of reactions and consequences in the Stress-Response-Sequence model. Persons with diabetes reacted to the stress of diabetes by applying a mix of primary and secondary appraisals that were associated with consequences of adherence to diet and HbA1c levels. The consequences of adherence were linked to the reactions of cognitive appraisal, specifically, adherence to general diet, specific diet, and HbA1c. For the consequence of adherence to general diet, the three cognitive appraisal variable of threat $(p=.02)$, harm/loss $(p=.05)$, and challenge $(p=.05)$ contributed significantly to the variance in days adherence to general diet recommendations (Figure 2). For the consequence of specific diet, the secondary appraisal variables of “nothing to do" and “can change” contributed significantly to the variance in days adherence to specific diet 
Figure 2. Cognitive appraisal and general diet

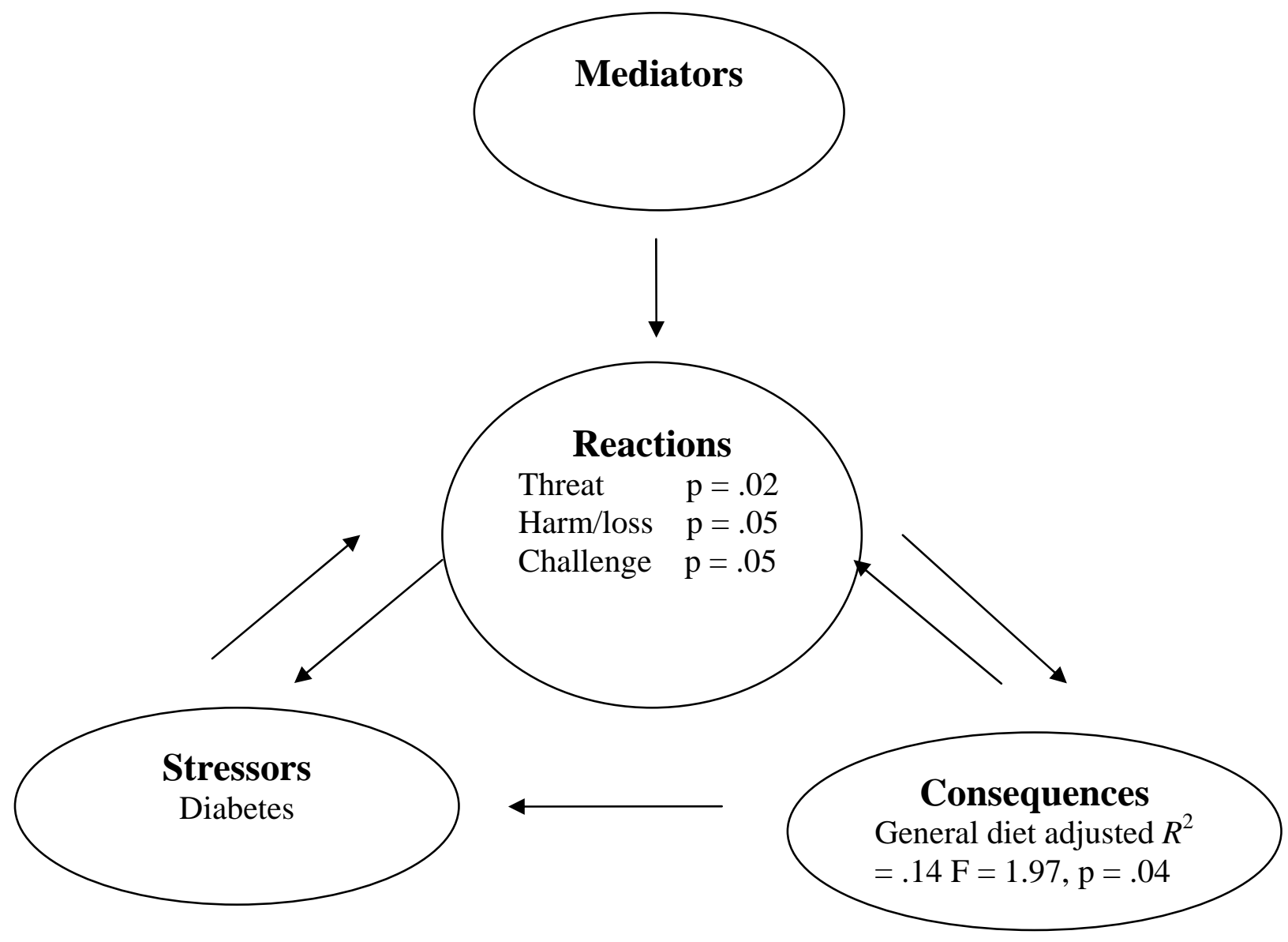


Figure 3. Cognitive appraisal and specific diet

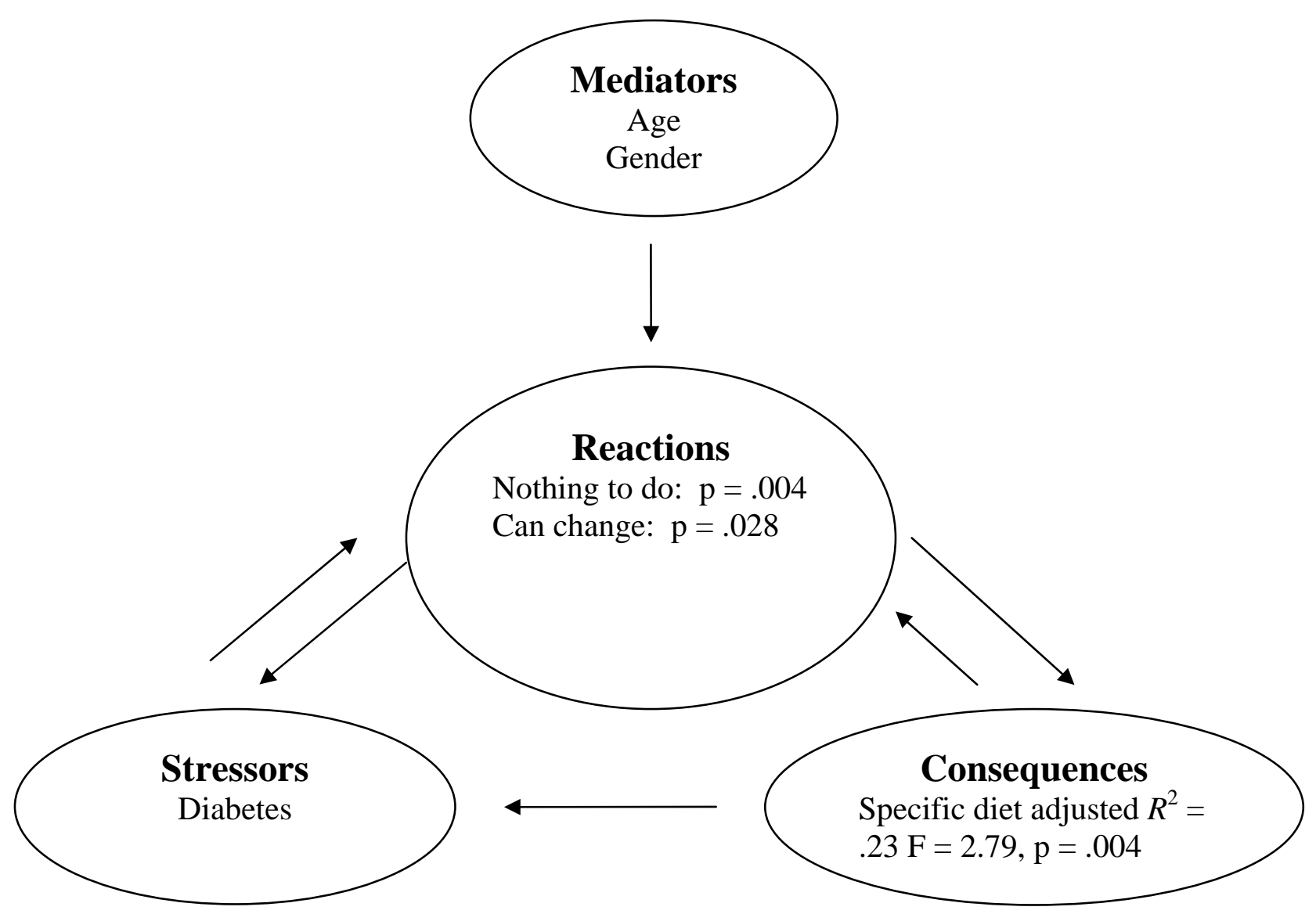


Figure 4. Cognitive appraisal and HbA1c

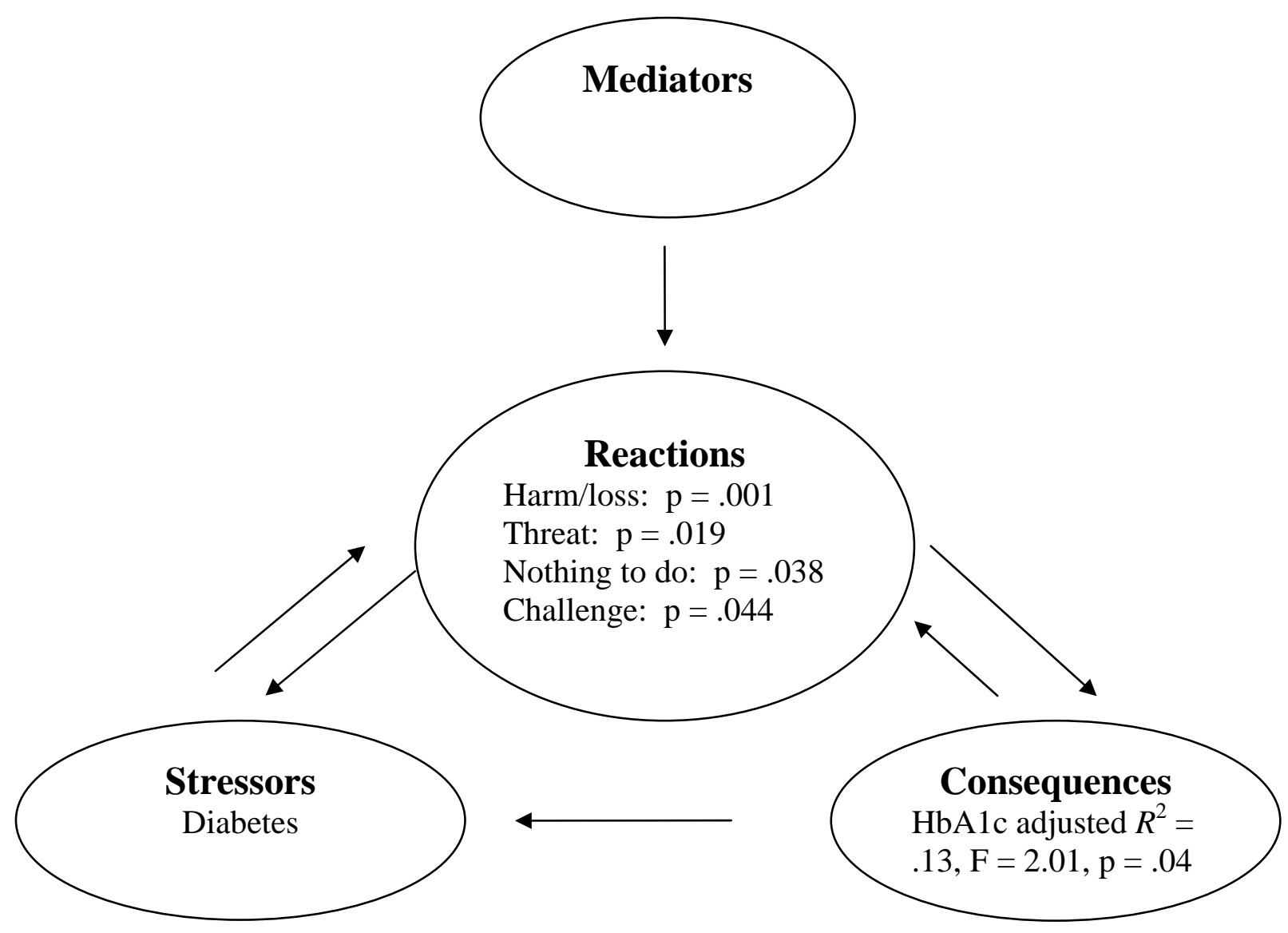


recommendations, while controlling for age and gender (Figure 3). For the consequence of HbA1c level, the cognitive appraisal variables of harm/loss, threat, "nothing to do”, and challenge contributed significantly to the variance in HbA1c level (Figure 4). The Stress-Response-Sequence (SRS) model provided a useful framework for studying these relationships.

\section{Nursing Implications}

\section{Adherence rates}

The persons with diabetes receiving care at the free clinic from this study did not differ in their levels of adherence to self-management behaviors from other types of patients reported in the literature. Lifestyle modifications focusing on diet and exercise have been emphasized in the care of patients with type 2 diabetes because of the effect on glycemic control (Rewers \& Hamman, 1995; Wing et al., 2001; ADA, 2008). Also, as proposed in the American Diabetes Association position statement on the Standards of Medical Care in Diabetes, the use of the oral medication metformin may be used for the prevention or delay of type 2 diabetes mellitus and at the time of diagnosis in combination with lifestyle modifications (Tuomilehto et al., 2001; Knowler et al., 2002), ADA, 2008).

The results of this study indicate that uninsured/underinsured persons with diabetes receiving care from a free clinic have high adherence to oral medications, and less with diet and exercise recommendations. Therefore, practitioners should consider treating persons with diabetes with medications sooner, while focusing on teaching lifestyle interventions targeting diet and exercise, as opposed to initially focusing on lifestyle modifications only. This implies that practitioners focus on both pharmacologic 
management and lifestyle modifications for the treatment of type 2 diabetes. For persons with diabetes in this study, high adherence to recommended oral medication taking may give them some success with glycemic control, and thus may motivate them to make further lifestyle modifications in the areas of diet and exercise, both of which were problematic in this study.

In terms of lifestyle modifications for this study population, healthcare providers should place emphasis on diet self-management behavior. Adherence to dietary recommendations plays a role in all levels of diabetes care, including primary, secondary, and tertiary prevention (ADA, 2008). Adherence to diet recommendations for the person with type 2 diabetes diet has been associated with weight loss and glycemic control. Studies have reported decreases in HbA1c of one to two percent in persons with type 2 diabetes (Pastors, Warshaw, Daly, Franz, \& Kulkarni, 2002; Pastors, Franz, Warshaw, Daly, \& Arnold, 2003; ADA, 2008).

Diet modification has been shown to be effective at promoting weight loss, whereas exercise and physical activity have only a modest weight loss effect (Klein et al., 2004; ADA, 2008). Furthermore, no specific successful interventions for exercise have been identified in the literature for persons with type 2 diabetes (Kavookjian et al., 2007). Many persons with type 2 diabetes may have physical limitations, including obesity, to the extent of requiring weight loss prior to engagement in physical activity.

Another consideration that needs attention when addressing lifestyle modifications is the effects of medication on diet and exercise. Patterns of glycemic control need to be established in persons taking oral hypoglycemic agents prior to beginning an exercise regimen. Those patterns are obtained by monitoring blood glucose 
in relation to oral medication prescribed and daily dietary patterns. Exercise is added and evaluated once those patterns are established. Given these relationships between oral medication and lifestyle modifications, and the issues of obesity and physical limitation in many persons with diabetes, lifestyle modification focusing on diet is the appropriate starting point for persons with type 2 diabetes.

\section{Appraisal of diabetes}

It is important to develop an understanding of how people with diabetes appraise their illness. Despite the fact that diabetes is a serious illness that presents serious threats and actual physical harm to ones health, the results of this study indicate that patients with diabetes perceived their diabetes as more of a challenge than a threat to their lives. These appraisals were associated with increased adherence to diet. More challenge appraisal may indicate a willingness to confront the problems associated with adherence to diabetes.

Knowledge of self-management behaviors alone is often not associated with glycemic control in persons with diabetes (Rothman et al., 2005a,b). Nurses need to help patients perceive diabetes in ways that are less threatening, and work to empower patients to face diabetes as a challenge. This may be accomplished by actively facilitating patient involvement in the planning of lifestyle modifications through identification of resources and goal setting specific to the person's needs and life circumstances. Having persons with diabetes create their own action plans, based on an assessment of their appraisal of diabetes, may be an effective way to assist in goal setting (Estabrooks, Glasgow, \& Dzewaltowski, 2003; Seligman et al., 2007). 


\section{Limitations}

The present study has several limitations that need to be acknowledged. First, the study design was based on a convenience sample of self-selected persons with diabetes. With self-selection the possibility exists that only the more adherent patients are more willing to participate in a study exploring adherence. Additionally, the generalizability of results is limited to the specific population of the study, given that the sample consisted of predominantly white, middle-aged females who had diabetes for less than ten years. Furthermore, the data collection was based on self-report.

Second, the sample size for this study was limited to 80 participants out of a potential of 248 patients being treated at the free clinic. Because of this sample size and the number of predictor variables being studied, the ability to demonstrate association and prediction was limited. This sample population presented with several recruitment challenges. Attendance at clinic appointments is unpredictable, with the cancelation rate being high for many patients. Another observed barrier was the willingness to complete forms that may identify the person. Although all surveys in this study contained no identifying information, many potential subjects were hesitant to participate. A third barrier was the hesitancy of potential subjects to interact with someone who was not part of the clinic staff. For these reasons, it was essential to have clinic staff involved in the study, from study planning to data collection.

A third limitation was the possibility of multicollinearity between variables, namely the harm/loss subscale and the threat subscale. These two variables were highly correlated, thus both subscales may be measuring attributes of the same concept. However, both variables were kept in the analysis because of theoretical implications. 
A final limitation was the ability of the current study to control for confounding factors that may influence the dependent variables. Many factors have been implicated as predictors of adherence, such as social support, finances, access to care, and knowledge. This study only controlled for select demographic and self-management variables.

\section{Future Research}

This study highlights the need for more research exploring the issues that persons with diabetes have with adherence to self-management behaviors, especially diet and exercise recommendations. As this study demonstrates, care provided free of charge does not solve the issues and barriers that patients have when it comes to being willing or able to follow treatment recommendations for a complex disease like diabetes. Additional research could explore cognitive appraisal of the stress of diabetes and adherence rates in the uninsured/underinsured that do not have access to a free clinic.

Future research could also explore the relationship between cognitive appraisal and adherence using additional self-reporting measures, such as finger stick logs and food logs, indirect measures such as pharmacy refill adherence, and more precise measures such as pill counts and electronic glucometer logs. Although no single measurement strategy has been accepted, the simultaneous use of both subjective and objective measures of adherence is the current state-of-the-art in measurement of adherence behaviors (World Health Organization, 2003). The use of additional measures of adherence may produce better models explaining adherence. It would also add strength to an adherence measure if adherence to self-management behaviors were measured over time. Measuring adherence at more than one time point would add 
stability to the measure, as well as provide insight about additional factors that may influence adherence, such as changes in illness perception.

Additional research could also explore measures of cognitive appraisal over time. Based on the Transactional Model of Stress and Coping, cognitive appraisals can be continuous and ever-changing while having certain stability over time (Lazarus \& Launier, 1978; Lazarus \& Folkman, 1984, 1987). Additionally, the distinction between threat and challenge can at times be obscure, and strongly dependent on ones perspective of the immediate environment. This distinction may also be simply a matter of positive versus negative tone. Measures of cognitive appraisal over time may provide insight about the influence of personal and situational factors and the relationship with adherence to self-management behaviors.

In terms of cognitive appraisal and outcome measures, this is the only study that has used the CAHS, or any theoretically complete measure of cognitive appraisal, in relation to adherence. In searching for predictors of treatment adherence, it is important to consider additional factors that may mediate how patients react to the stress of diabetes, such as duration of disease, health literacy, comprehension of instruction, comorbidities/physical health, coping skills and adjustment to illness.

The literature provides mixed findings regarding the duration of diabetes and its association with self-management behaviors and diabetes control. Duration of diabetes has been found to be associated with self-management behaviors and HbAlc levels, such that longer duration of diabetes is associated with increased adherence to selfmanagement behaviors (Krapek et al., 2004; Mateo et al., 2006). Other studies have 
found no association between duration of diabetes and diabetes self-management behaviors and control (Rhee et al., 2005; Hartz et al., 2006).

Health literacy and the ability to comprehend health information may also serve as a factor in adherence to self-management behaviors. Low health literacy has been identified as an issue for the uninsured (Ratzan \& Parker, 2000; Barrett, 2006). It has been associated with less desire to participate in health-related decision making (DeWalt, Boone, \& Pignone, 2007). It has also been identified that comprehension of health information requires attention to more than just reading level (Seligman et al., 2007).

The existence of co-morbidities may also have impact on the adherence to selfmanagement behaviors. In addition to the overwhelming demands of managing diabetes mellitus, the presence of co-morbidities adds to this complexity, and thus may affect both cognitive appraisal and adherence to self-management recommendations.

It may be beneficial to compare appraisal of the stress of diabetes with additional psychosocial outcome measures such as coping skills and adjustment to illness. Measurement and stress in terms of problem-focused and emotion-focused coping has produced much knowledge in terms of how individuals respond to stress. Adding the component of appraisal along with the measurement of coping may provide more information into the reasons why individuals with diabetes have difficulty adhering to self-management behaviors.

\section{Conclusion}

Although much has been learned about predictors of treatment adherence, many gaps exist in this large body of literature. Understanding how an individual appraises potentially stressful events is important when facing a stressor such as the threat and 
treatment of illness. Understanding the cognitive appraisal of illness and how it relates to other factors may provide insight into the reasons why patients have difficulty with treatment adherence. Applying measures of cognitive appraisal to studies examining treatment adherence may help to fill gaps in knowledge related to patient behavior. 


\section{Appendix A}

\section{COGNITIVE APPPRAISAL OF HEALTH SCALE}

Below are several statements that describe ways people think about their diabetes. Please read each item and circle one number that best describes how much you agree or disagree with the statement according to what is happening to you right now.

The answers range from strongly agree (5) to strongly disagree (1). Please be sure to answer all statements. There are no right or wrong answers.

$\begin{array}{cccc}\text { strongly disagree } & \text { undecided agree } & \begin{array}{c}\text { strongly } \\ \text { agree }\end{array} \\ \text { disagree }\end{array}$

1. I can control what will happen to me.

1

2

3

4

5

2. Diabetes won't get me down.

1

2

3

4

5

3. I have not been able to do what I want to

1

2

3

4

5 do because I have diabetes.

4. Diabetes is frightening to me.

1

2

3

4

5

5. Diabetes isn't stressful to me.

1

2

3

4

5

6. Things will only get worse because of

1

2

3

4

5 having diabetes.

7. My diabetes will not go well.

1

2

3

4

5

8. Having diabetes has damaged my life.

1

2

3

4

5

9. I have lost interest in the things around me. 1

2

3

4

5

10. I have had to give up a great deal because

1

2

3

4

5 of having diabetes.

11. I can beat diabetes despite the difficulties. 1

2

3

4

5

12. Having diabetes is something that I can

1

2

3

4

5 change or do something about.

13. I have a sense of loss over the things I can 1 2 no longer do. 


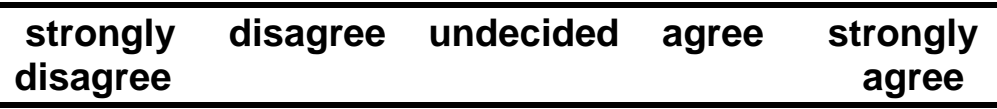

14. I feel I can handle having diabetes.

1

2

3

4

5

15. I have nothing to lose because of having

1

2

3

4

5 diabetes.

16. Because of having diabetes, I have to hold

1

2

3

4

5 myself back from doing what I want to do.

17. I have a lot to lose because of having

1

2

3

5 diabetes.

18. I worry about what will happen to me.

1

2

3

4

5

19. Relationships with my family and friends

1

2

3

4

5 have suffered.

20. There is nothing I need to do for my diabetes.

1

2

3

4

5

21. I have been harmed in some way by

1

2

3

4

5 having diabetes.

22. I need to know more before I can do

1

2

3

4

5 anything about my diabetes.

23. I don't think much about my diabetes.

1

2

3

4

5

24. This health condition has caused me to learn 1 more about myself.

2

3

4

5

25. I have been hurt by my diabetes.

1

2

3

4

5

26. There is a lot I can do to overcome my

1

2

3

4

5 diabetes.

27. I have to accept having diabetes.

1

2

3

4

5

28. Diabetes doesn't affect my life.

1

2

3

4

5

(c) 1993, Theresa Kessler 


\section{Scoring for the CAHS}

There are four separate scales for primary appraisal (threat, challenge, harm/loss, and benign/irrelevant) and 5 items that measure aspects of secondary appraisal. Subjects are asked to respond to each item on the CAHS based on their cognitive appraisal of their current health condition. Subjects may be asked to respond to the items in relation to a specific health condition (the name of the condition could be inserted in each item to replace "this health condition"). All items are scored on a 5-point Likert scale ranging from 1 (strongly disagree) to 5 (strongly agree). Higher scores on each scale or item indicate greater agreement with that appraisal.

Primary appraisal Threat scale - 5 items $(4,6,7,17,18)$; score range 5 to 25

dimensions: Challenge scale - 6 items $(1,2,11,14,24,26)$; score range 6 to 30 Harm/Loss scale - 8 items $(3,8,9,10,13,19,21,25)$; score range 8 to 40 Benign/Irrelevant scale - 4 items $(5,15,23,28)$; score range 4 to 20

Secondary appraisal dimensions:
Items: 12, 16, 20, 22, 27; scores range from 1 to 5 for each item 


\section{Appendix B}

\section{Summary of Diabetes Self-Care Activities (Diet, Exercise, and Medication Taking Subscales)}

The questions below ask you about your diabetes self-care activities during the past 7 days. If you were sick during the past 7 days, please think back to the last 7 days that you were not sick.

\section{$\underline{\text { Diet }}$}

1. How many of the last SEVEN DAYS have you followed a healthful eating plan?

$$
\begin{array}{llllllll}
0 & 1 & 2 & 3 & 4 & 5 & 6 & 7
\end{array}
$$

2. On average, over the past month, how many DAYS PER WEEK have you followed your eating plan?

$$
\begin{array}{llllllll}
0 & 1 & 2 & 3 & 4 & 5 & 6 & 7
\end{array}
$$

3. On how many of the last SEVEN DAYS did you eat five or more servings of fruits and vegetables?

$$
\begin{array}{llllllll}
0 & 1 & 2 & 3 & 4 & 5 & 6 & 7
\end{array}
$$

4. On how many of the last SEVEN DAYS did you eat high fat foods such as red meat or full-fat dairy products?

$\begin{array}{llllllll}0 & 1 & 2 & 3 & 4 & 5 & 6 & 7\end{array}$

\section{Exercise}

5. On how many of the last SEVEN DAYS did you participate in at least 30 minutes of physical activity? (Total minutes of continuous activity, including walking).

$$
\begin{array}{llllllll}
0 & 1 & 2 & 3 & 4 & 5 & 6 & 7
\end{array}
$$

6. On how many of the last SEVEN DAYS did you participate in a specific exercise session (such as swimming, walking, biking) other than what you do around the house or as part of your work?

$\begin{array}{llllllll}0 & 1 & 2 & 3 & 4 & 5 & 6 & 7\end{array}$




\section{$\underline{\text { Medications }}$}

6A. On how many of the last SEVEN DAYS did you take your recommended diabetes medication?

$\begin{array}{llllllll}0 & 1 & 2 & 3 & 4 & 5 & 6 & 7\end{array}$

\section{INSULIN USERS}

7A. On how many of the last SEVEN DAYS did you take your recommended insulin injections?

$\begin{array}{llllllll}0 & 1 & 2 & 3 & 4 & 5 & 6 & 7\end{array}$

8A. On how many of the last SEVEN DAYS did you take your recommended number of diabetes pills?

$\begin{array}{llllllll}0 & 1 & 2 & 3 & 4 & 5 & 6 & 7\end{array}$

\section{Scoring for the SDSCA}

General diet $=$ Mean number of days for items 1 and 2.

Specific diet $=$ Mean number of days for items 3 and 4 , reversing item $4(0=7,1=6,2=5$, $3=4,4=3,5=2,6=1,7=0)$.

Exercise $=$ Mean number of days for items 5 and 6 .

Medications = Use item 6A $-\mathrm{OR}-7 \mathrm{~A}$ AND 8A; use total number of days for item 6A, use mean number of days if both 7A and $8 \mathrm{~A}$ are applicable. 


\section{Appendix C}

November 16, 2007

\section{Dear Participant,}

Please consider completing the enclosed questionnaires which are part of a study that I am conducting to better understand how a person's beliefs about having diabetes affects how they manage their health. This study is part of my work toward a doctorate degree in the West Virginia University School of Nursing.

The study involves completing the enclosed questionnaires. It is estimated that your participation will take about 10-15 minutes. Participation in the study is voluntary. Once you agree to participate you do not have to answer all of the questions. No information is requested that would identify you.

There are no known risks or discomfort associated with this study. Your care will in no way be affected by your participation in this study or by the responses you share. If the questions cause you to be concerned or upset, please contact one of the Health Right staff at the front desk for further assistance.

If you want more information about this research, you may call me at my office (304293-1401) or that of my faculty advisor, Dr. Cynthia Persily (304-347-1253). For information about your rights as a research participant, you may contact the Office of Research Compliance at West Virginia University at 293-7073. Thank you for your assistance.

Sincerely,

\section{Roger Carpenter, RN}

West Virginia University School of Nursing 


\section{The Summary of Diabetes Self-Care Activities}

The questions below ask you about your diabetes self-care activities during the past 7 days. If you were sick during the past 7 days, please think back to the last 7 days that you were not sick.

\section{$\underline{\text { Diet }}$}

1. How many of the last SEVEN DAYS have you followed a healthful eating plan?

$\begin{array}{llllllll}0 & 1 & 2 & 3 & 4 & 5 & 6 & 7\end{array}$

2. On average, over the past month, how many DAYS PER WEEK have you followed your eating plan?

$\begin{array}{llllllll}0 & 1 & 2 & 3 & 4 & 5 & 6 & 7\end{array}$

3. On how many of the last SEVEN DAYS did you eat five or more servings of fruits and vegetables?

$\begin{array}{llllllll}0 & 1 & 2 & 3 & 4 & 5 & 6 & 7\end{array}$

4. On how many of the last SEVEN DAYS did you eat high fat foods such as red meat or full-fat dairy products?

$\begin{array}{llllllll}0 & 1 & 2 & 3 & 4 & 5 & 6 & 7\end{array}$

\section{$\underline{\text { Exercise }}$}

5. On how many of the last SEVEN DAYS did you participate in at least 30 minutes of physical activity? (Total minutes of continuous activity, including walking).

$\begin{array}{llllllll}0 & 1 & 2 & 3 & 4 & 5 & 6 & 7\end{array}$

6. On how many of the last SEVEN DAYS did you participate in a specific exercise session (such as swimming, walking, biking) other than what you do around the house or as part of your work?

$\begin{array}{llllllll}0 & 1 & 2 & 3 & 4 & 5 & 6 & 7\end{array}$




\section{$\underline{\text { Medications }}$}

6A. On how many of the last SEVEN DAYS did you take your recommended diabetes medication?

$\begin{array}{llllllll}0 & 1 & 2 & 3 & 4 & 5 & 6 & 7\end{array}$

\section{INSULIN USERS}

7A. On how many of the last SEVEN DAYS did you take your recommended insulin injections?

$\begin{array}{llllllll}0 & 1 & 2 & 3 & 4 & 5 & 6 & 7\end{array}$

8A. On how many of the last SEVEN DAYS did you take your recommended number of diabetes pills?

$\begin{array}{llllllll}0 & 1 & 2 & 3 & 4 & 5 & 6 & 7\end{array}$


Below are several statements that describe ways people think about their diabetes. Please read each item and circle one number that best describes how much you agree or disagree with the statement according to what is happening to you right now.

The answers range from strongly agree (5) to strongly disagree (1). Please be sure to answer all statements. There are no right or wrong answers.

strongly

disagree

1. I can control what will happen to me.

2. Diabetes won't get me down.

3. I have not been able to do what I want to do because I have diabetes.

4. Diabetes is frightening to me.

5. Diabetes isn't stressful to me.

6. Things will only get worse because of having diabetes.

7. My diabetes will not go well.

8. Having diabetes has damaged my life.

9. I have lost interest in the things around me.

10. I have had to give up a great deal because of having diabetes.

11. I can beat diabetes despite the difficulties. 1

12. Having diabetes is something that I can change or do something about.

13. I have a sense of loss over the things I can no longer do.

1

1

1

1

1

1

1

1

1

1

1

1

1

1

1

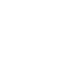

2

2

2

2

3

agree

strongly

agree 
14. I feel I can handle having diabetes.

15. I have nothing to lose because of having diabetes.

16. Because of having diabetes, I have to hold myself back from doing what I want to do.

17. I have a lot to lose because of having diabetes.

18. I worry about what will happen to me.

19. Relationships with my family and friends have suffered.

20. There is nothing I need to do for my diabetes.

21. I have been harmed in some way by having diabetes.

22. I need to know more before I can do anything about my diabetes.

23. I don't think much about my diabetes.

24. This health condition has caused me to learn more about myself.

25. I have been hurt by my diabetes.

1 diabetes.

27. I have to accept having diabetes.

28. Diabetes doesn't affect my life.

1

1

2

3

3

4

5
5

5

5

5

5

5

5

5

5

5

5

5

5

5 


\section{Subject Demographic Form}

Age:

Sex: Male

Female

\section{Ethnicity:}

White

African American

Asian

Marital status:

\section{Education:}

Single

Married

Divorced

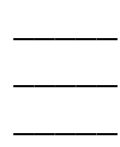

Hispanic

Native American

Other

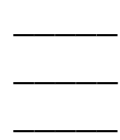

Separated

Widowed

Significant other

Less than high school

Graduated high school

Some college

College graduate

Masters degree

Doctorate

GED

\section{How long have you had diabetes?}

Less than 5 years:

Between 5 to 10 years:

More than 10 years:

\section{Co-morbidities:}

Besides having diabetes, do you have any other medical problems?

Yes / No 


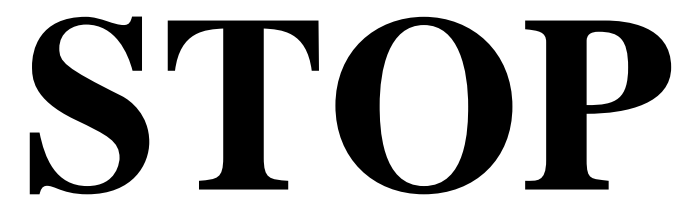

\section{Give this packet to the nurse you see today}

Hemoglobin A1c (to be recorded on this form by your health care provider):

Most current level:

Interval since last test:

Days

Weeks

Months 


\section{Appendix D}

General Diet

\section{Normal Q-Q Plot of Unstandardized Residual}

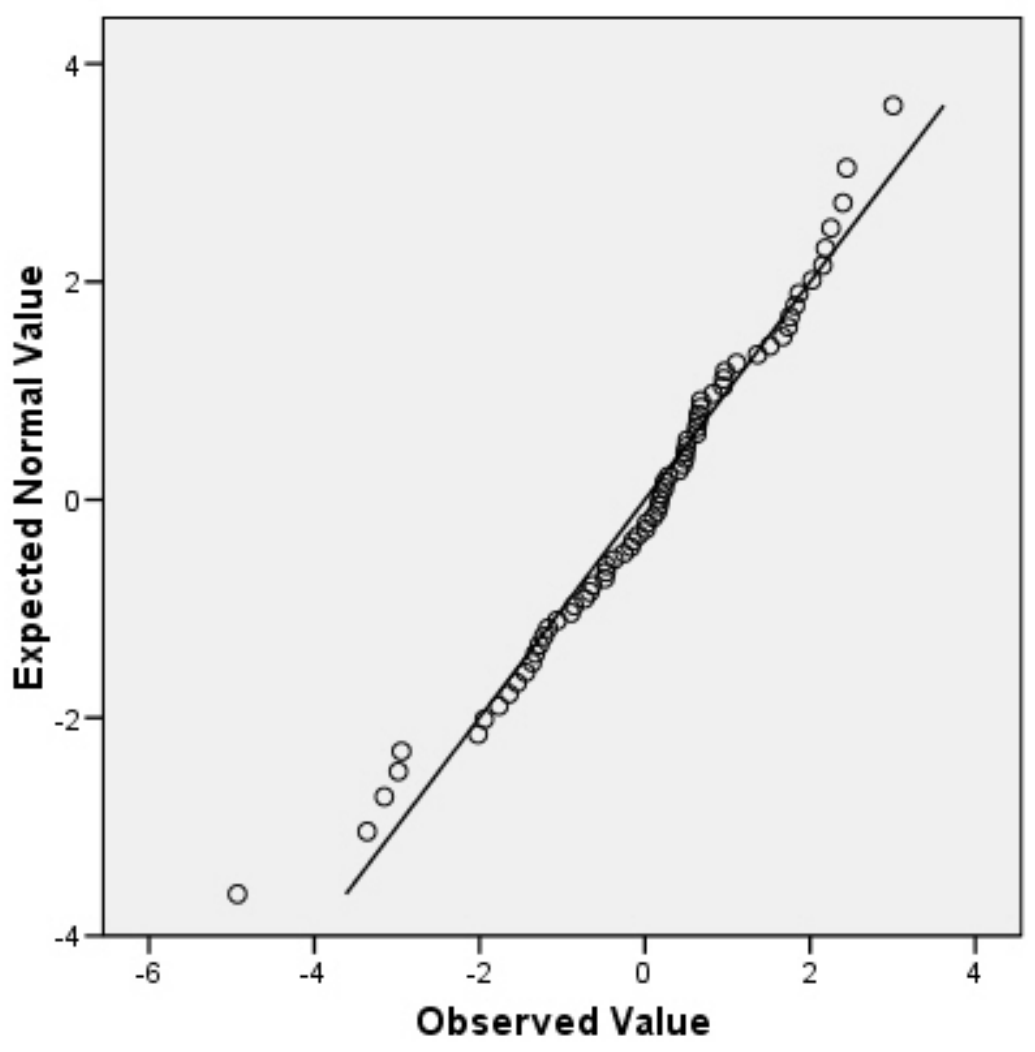


Specific Diet

Normal Q-Q Plot of Unstandardized Residual

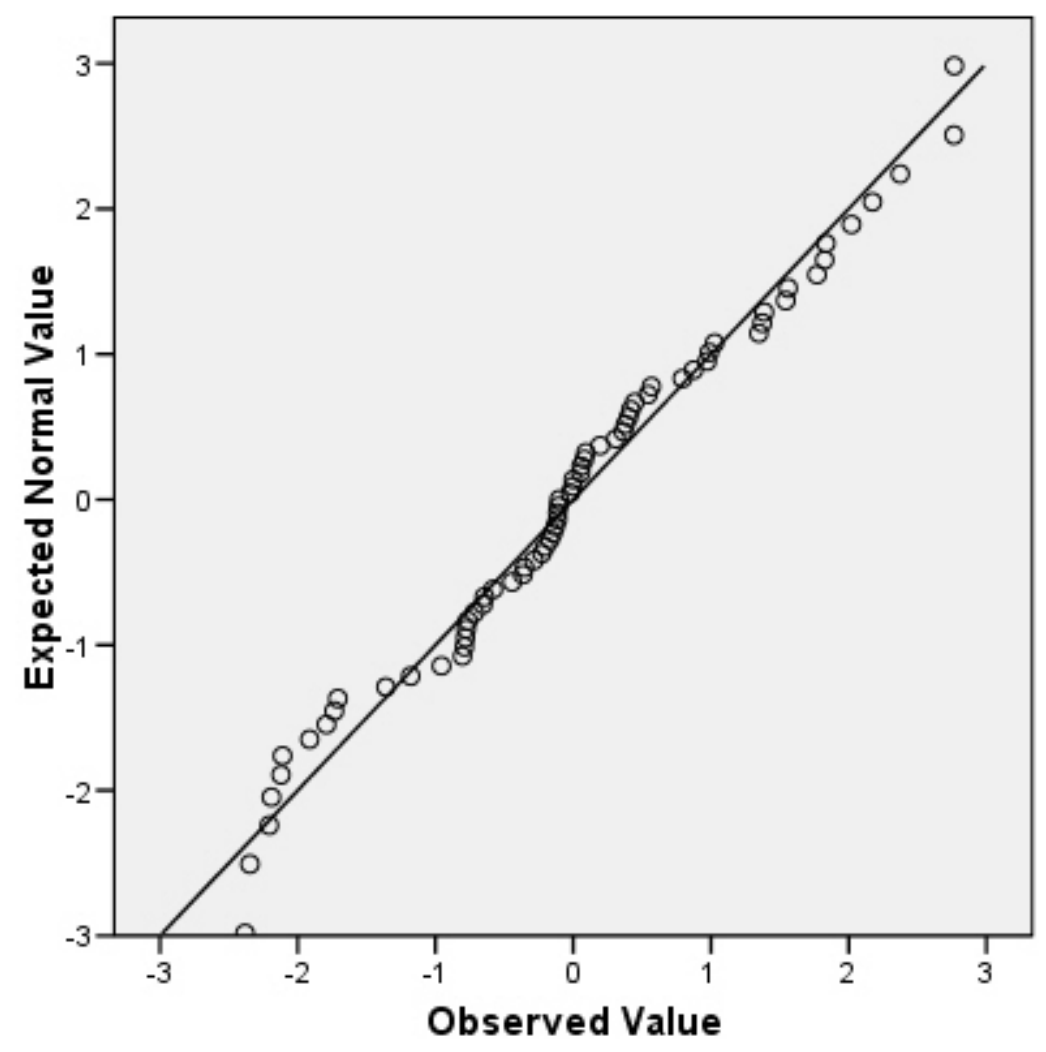


Exercise

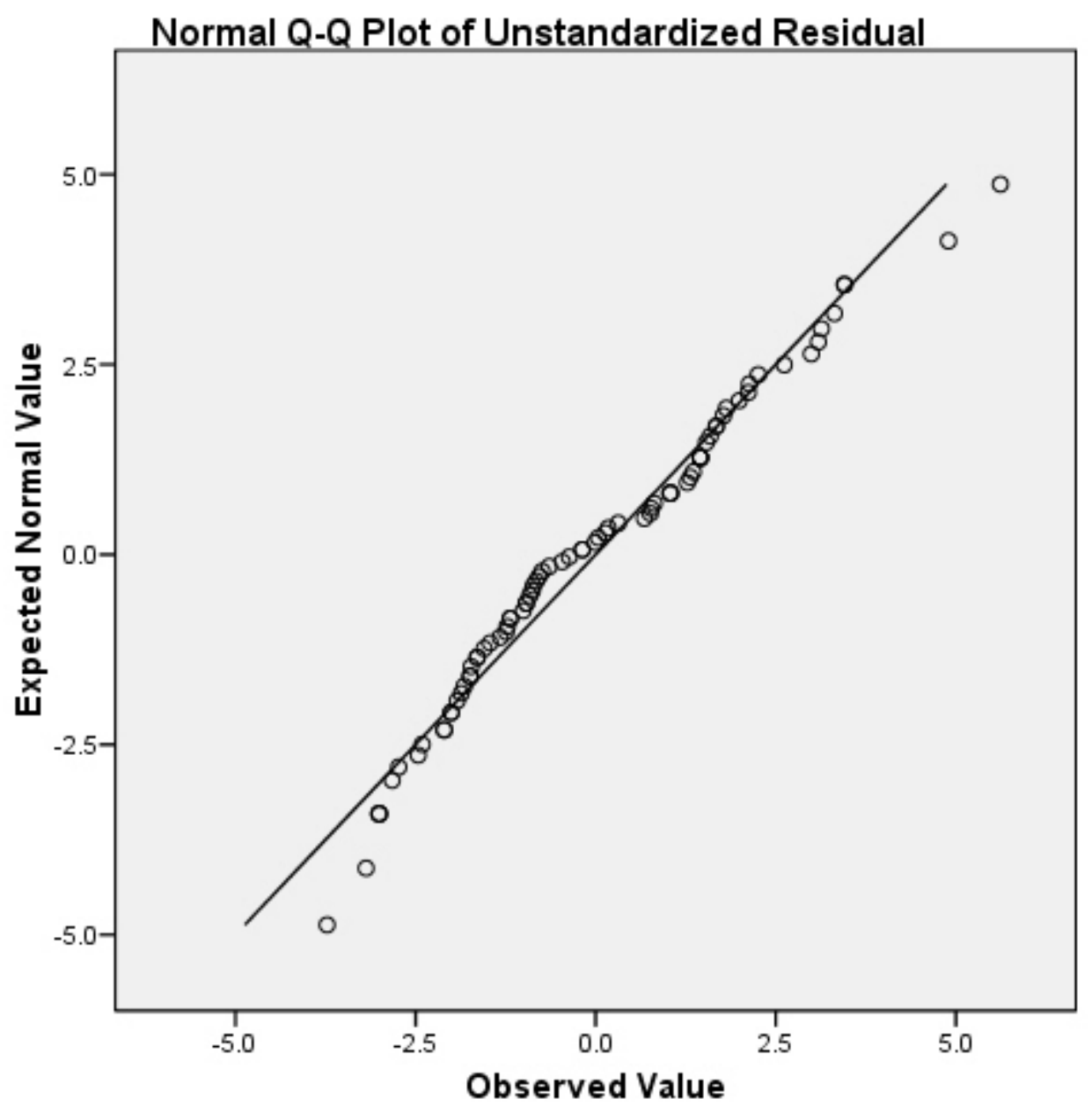


HbA1c

Normal Q-Q Plot of Unstandardized Residual

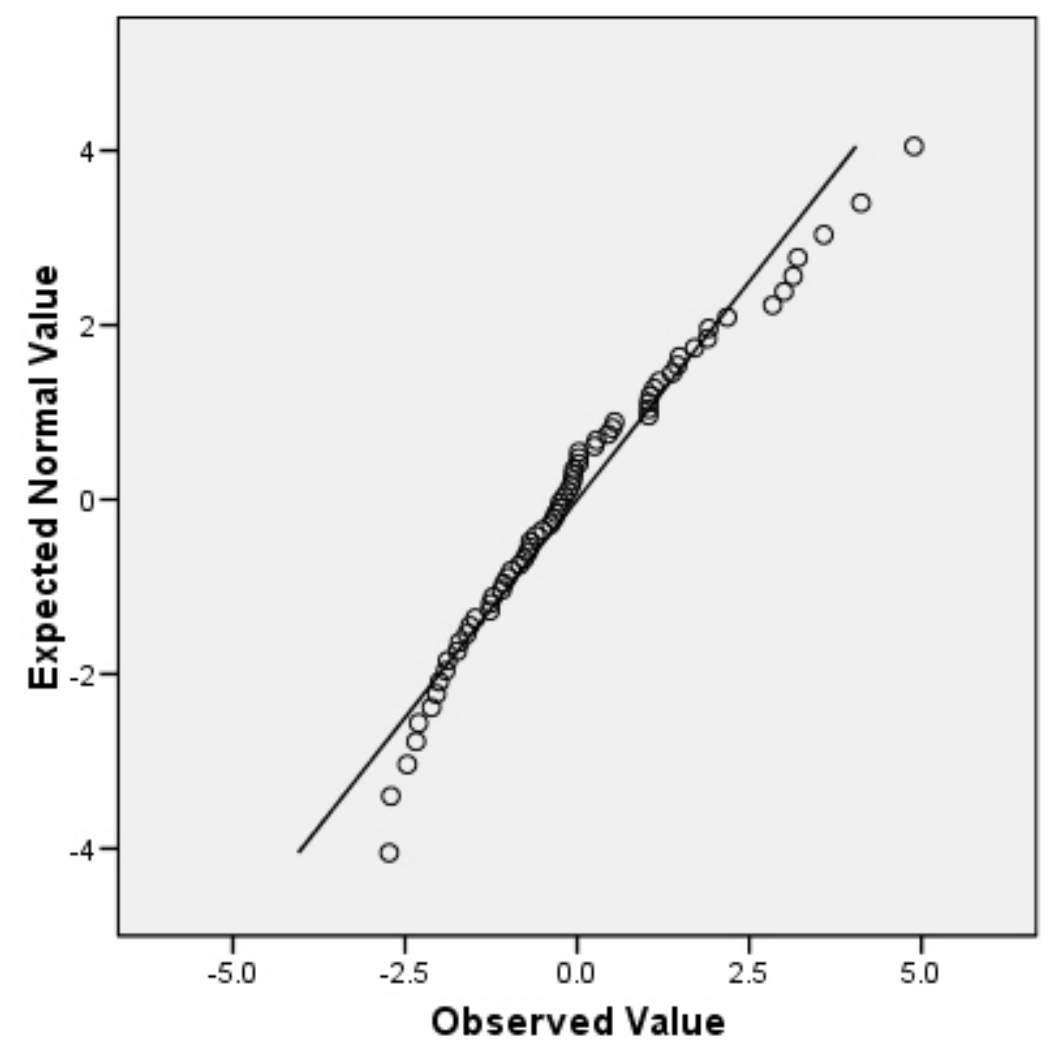


Appendix E

\section{Scatterplot}

Dependent Variable: General Diet Average

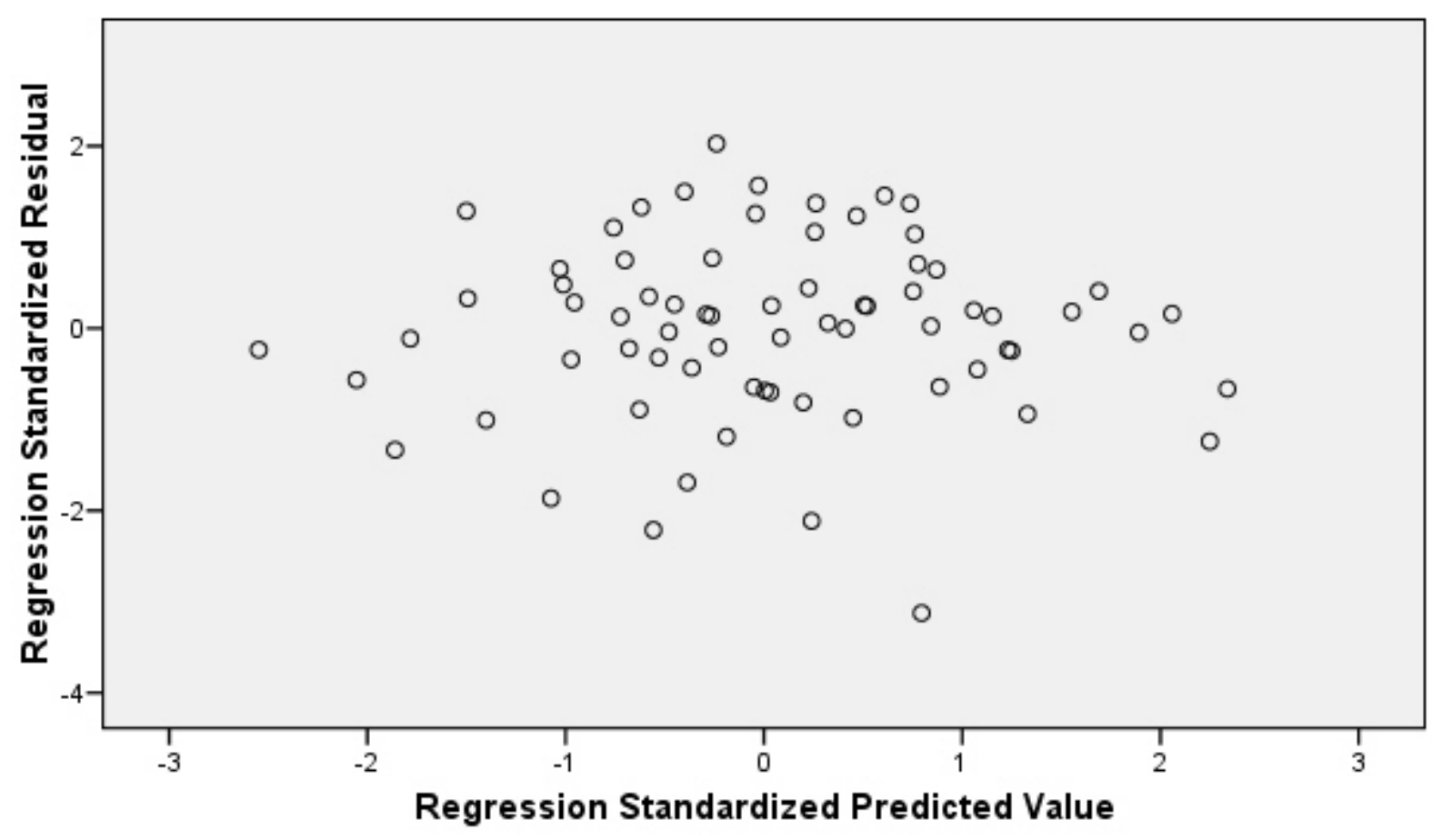




\section{Scatterplot}

Dependent Variable: Specific diet average

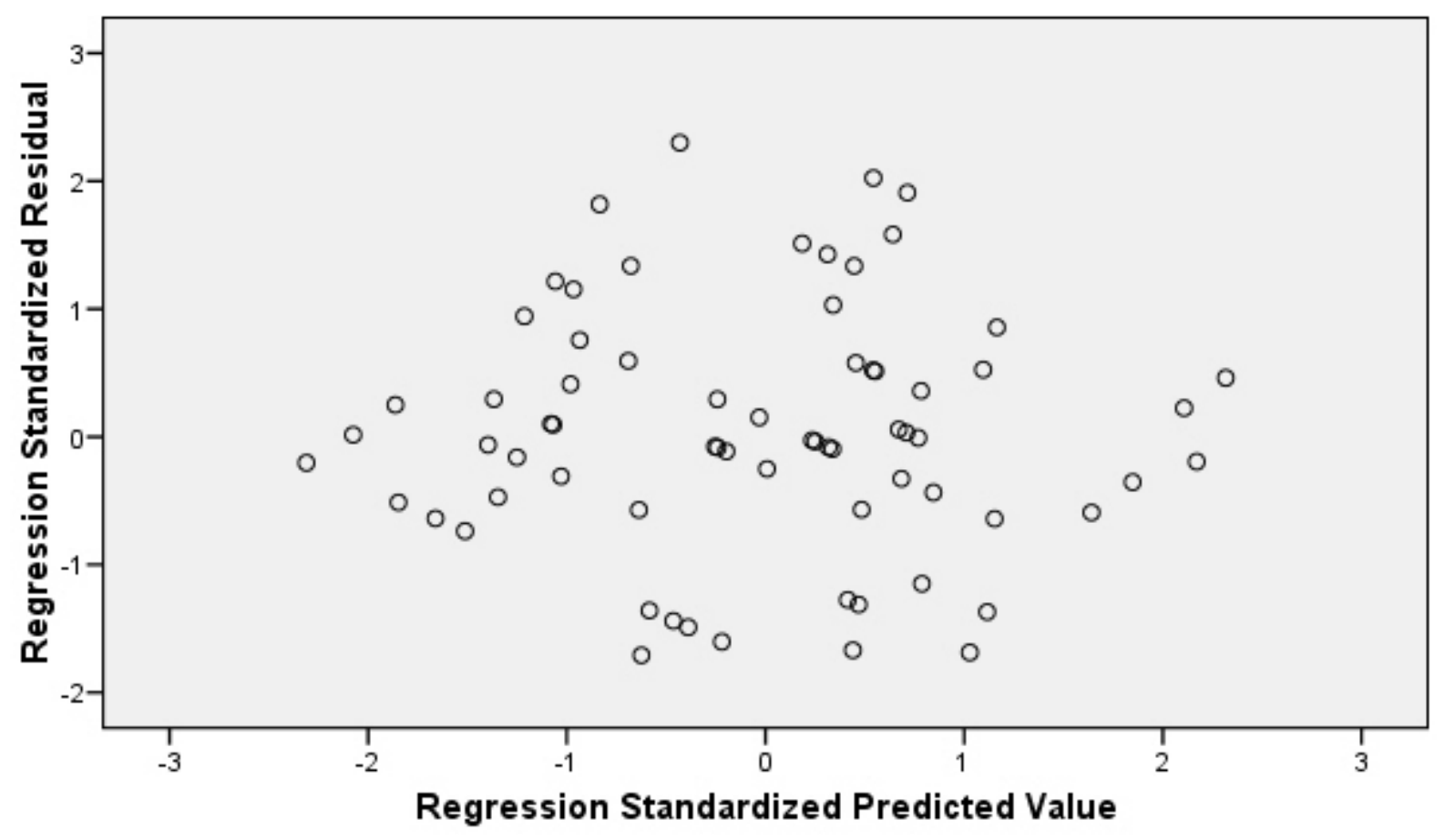




\section{Scatterplot}

\section{Dependent Variable: Exercise average}

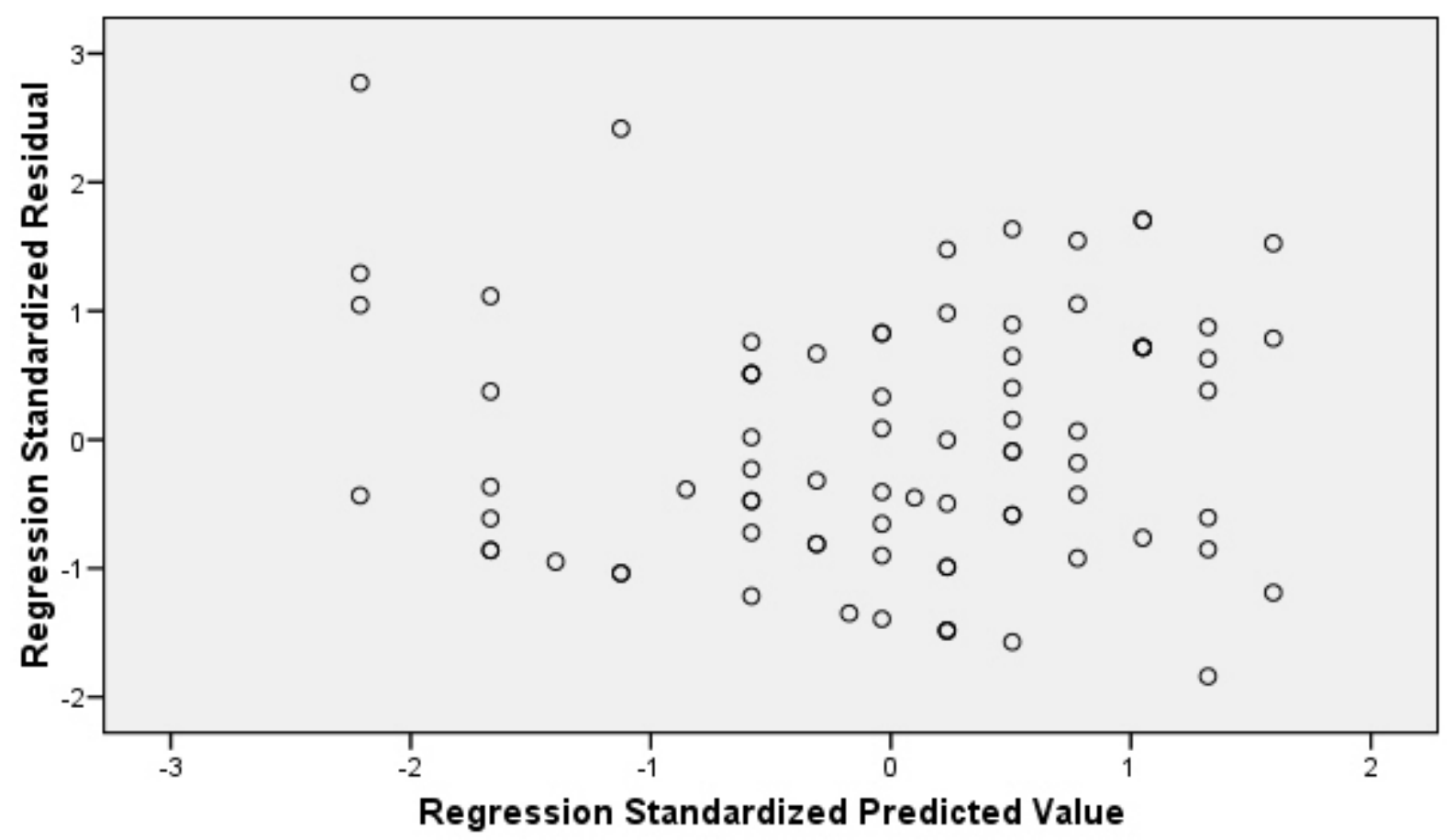


Scatterplot

Dependent Variable: HBA1C

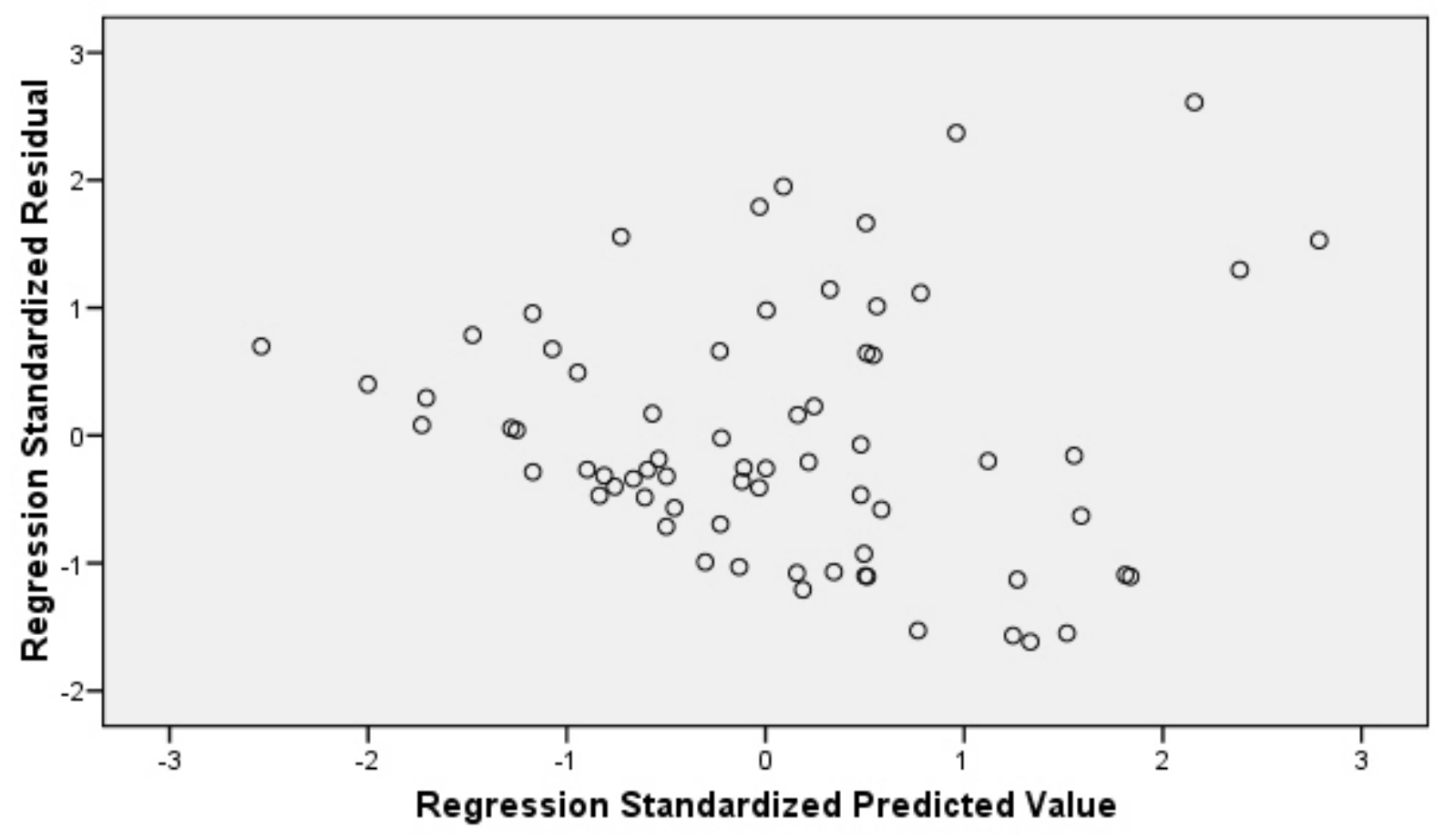




\section{BIBLIOGRAPHY}

Ahmad, M. (2005). Psychometric evaluation of the cognitive appraisal of health scale with patients with prostate cancer. Journal of Advanced Nursing, 49, 78-86.

Ahmad, M., Musil, C., Zauszniewski, J., \& Resnick, M. (2005). Prostate cancer: Appraisal, coping, and health status. Journal of Gerontological Nursing, 31, 34-43.

American Cancer Society. (1996). Cancer statistics: A measure of progress. CA A Cancer Journal for Clinicians, 46, 9-27.

American Diabetic Association. (2008). American diabetic association: Clinical practice recommendations 2008. Diabetes Care, 31, S1-S104.

Anderson, R. M. \& Funnell, M. M. (2000). Compliance and adherence are dysfunctional concepts in diabetes care. The Diabetes Educator, 26, 597-604.

Ayanian, J. Z., Weissman, J. S., Schneider, E. C., Ginsburg, J. A., \& Zaslavsky, A. M. (2000). Unmet health needs of uninsured adults in the United States. Journal of the American Medical Association, 284, 2061-2069.

Baker, D. W., Shapiro, M. F., \& Schur, C. L. (2000). Health insurance and access to care for symptomatic conditions. Archives of Internal Medicine, 160, 1269-1274.

Barrett, S.E. (2006). Health literacy: Improving quality of care in primary care settings. Journal of Health Care for the Poor and Underserved, 17, 690-697. 
Bartels, D. (2004). Adherence to oral therapy for type 2 diabetes: Opportunities for enhancing glycemic control. Journal of the American Academy of Nurse Practitioners, 16, 8-16.

Beckles, G., Engelgau, M. M., Narayan, K. M., Herman, W. H., Aubert, R. E., \& Williamson, D. F. (1998). Population-based assessment of the level of care among adults with diabetes in the U.S. Diabetes Care, 21, 1432-1438.

Boccuzzi, S. J., Wogen, J., Fox, J., Sung, J., Shah, A. B., \& Kim, J. (2001). Utilization of oral hypoglycemic agents in a drug-insured U.S. population. Diabetes Care, 24, 1411-1415.

Bova, C. \& Durante, A. (2003). Sexual functioning among HIV-infected women. AIDS Patient Care and STDs, 17, 75-83.

Browne, G. B., Byrne, C., Roberts, J., Streiner, D., Fitch, M., Corey, P. et al. (1988). The meaning of illness questionnaire: Reliability and validity. Nursing Research, 37, 368-373.

Carpenter, R. (2005). Perceived threat in compliance and adherence research. Nursing Inquiry, 12, 193-199.

Carpenter, R. (2007). Pilot testing of the cognitive appraisal of health scale. Ref Type: Unpublished Work

Centers for Disease Control and Prevention. (2005). National diabetes fact sheet. Ref Type: Pamphlet 
Ciechanowski, P., Russo, J., Katon, W., Von Korff, M., Ludman, E., Lin, E. et al. (2004). Influence of patient attachment style on self-care and outcomes in diabetes. Psychosomatic Medicine, 66, 720-728.

Cohen, J.W. (1988). Statistical power analysis for the behavioral sciences $\left(2^{\text {nd }}\right.$ edn). Hillsdale, NJ: Lawrence Erlbaum Associates.

Cohen, M. (2002). First-degree relatives of breast-cancer patients: Cognitive perceptions, coping, and adherence to breast self-examination. Behavioral Medicine, 28, $15-22$.

Cramer, J. A. (2004). A systematic review of adherence with medications for diabetes. Diabetes Care, 27, 1218-1224.

Croyle, R. T. (1992). Appraisal of health threats: cognition, motivation, and social comparison. Cognitive Therapy and Research, 16, 165-182.

Dailey, G. (2007). Assessing glycemic control with self-monitoring of blood glucose and hemoglobin A1c measurements. Mayo Clinic Proceedings, 82(2), 229-236.

Delahanty, L. M., Grant, R. W., Wittenberg, E., Bosch, J. L., Wexler, D. J., Cagliero, E. et al. (2007). Association of diabetes-related emotional distress with diabetes treatment in primary care patients with type 2 diabetes. Diabetic Medicine, 24, 48-54.

Delaronde, S. (2007). Barriers to A1C testing among a managed care population. The Diabetes Educator, 31(2), 235-239. 
DeWalt, D.A., Boone, R.S., \& Pignone, M.P. (2007). Literacy and its relationship with self-efficacy, trust, and participation in medical decision making. American Journal of Health Behavior, 31, suppl 1, S27-S35.

Dezii, C., Kawabata, H., \& Tran, M. (2002). Effects of once-daily and twice-daily dosing on adherence with prescribed glipizide oral therapy for type 2 diabetes. Southern Medical Journal, 95, 68-71.

Donnan, P. T., MacDonald, T. M., \& Morris, A. D. (2002). Adherence to prescribed oral hypoglycaemic medication in a population of patients with type 2 diabetes: A retrospective cohort study. Diabetic Medicine, 19, 279-284.

Dunbar-Jacob, J. \& Schlenk, E. (2001). Patient adherence to treatment regimen. In A.Baum, T. Revenson, \& J. Singer (Eds.), Handbook of Health Psychology (pp. 571580). Mahwah, New Jersey: Lawrence Erlbaum Associates.

Dunbar, S., Jenkins, L. S., Hawthorne, M., Kimble, L., Dudley, W., \& Slemmons, M. P. J. (1999). Factors associated with outcomes 3 months after implantable cardioverter defibrillator insertion. Heart \& Lung, 28, 303-315.

Dunbar, S. B., Jenkins, L. S., Hawthorne, M., \& Porter, L. S. (1996). Mood disturbance in patients with recurrent ventricular dysrhythmia before insertion of implantable cardioverter defibrillator. Heart \& Lung, 25, 253-261.

Elliott, G. R. \& Eisdorfer, C. (1982). Conceptual issues in stress research. In G.R.Elliott \& C. Eisdorfer (Eds.), Stress and Human Health (pp. 11-24). New York: Springer Publishing Company. 
Estabrooks, P.A., Glasgow, R.E., \& Dzewaltowski, D.A. (2003). Physical activity promotion through primary care. Journal of the American Medical Association, 289(22), 2913-2916.

Fisher, E. B., Brownson, C. A., O'Toole, M. L., Shetty, G., Anwuri, V., Fazzone, P. et al. (2007). The robert wood johnson foundation diabetes initiative: Demonstration projects emphasizing self-management. The Diabetes Educator, 33, 83-94.

Folkman, S. (1984). Personal control and stress and coping processes: a theoretical analysis. Journal of Personality and Social Psychology, 46, 839-852.

Folkman, S. \& Lazarus, R. S. (1985). If it changes it must be a process: Study of emotion and coping during three stages of a college examination. Journal of Personality and Social Psychology, 48, 150-170.

Folkman, S. \& Lazarus, R. S. (1988). Coping as a mediator of emotion. Journal of Personality and Social Psychology, 54, 466-475.

Ford, M. E., Havstad, S. L., Brooks, B. L., \& Tilley, B. C. (2002). Perceptions of diabetes among patients in an urban health care system. Ethnicity \& Health, 7, 243-254.

Gillibrand, R. \& Stevenson, J. (2006). The extended health belief model applied to the experience of diabetes in young people. British Journal of Health Psychology, 11, 155-169. 
Grant, R.W., Devita, N.G., Singer, D.E., \& Meigs, J.B. (2003). Polypharmacy and medication adherence in patients with type 2 diabetes. Diabetes Care, 26(5), 14081412.

Grant, R., Adams, A.S., Trinacty, C.M., Zhang, F., Kleinman, K., Soumerai, S.B., et al. (2007). Relationship between patient medication adherence and subsequent clinical inertia in type 2 diabetes glycemic management. Diabetes Care, 30(4), 807-812.

Grossman, M., Lee, V., Kenny, J.V., McHarg, L., Godin, M., \& Chambers-Evans, J. (2000). Psychological adjustment of critically injured patients three months after an unexpected, potentially life-threatening accident. Journal of Clinical Nursing, 9, 801815.

Hamama-Raz, Y., \& Solomon, Z. (2006). Psychological adjustment of melanoma survivors: the contribution of hardiness, attachment, and cognitive appraisal. Journal of Individual Differences, 27(3), 172-182.

Harris, M. I. (1995). Summary. In C.C.Cowie, P. H. Stern, Boyko E.J., G. E. Reiber, \& P. H. Bennett (Eds.), Diabetes in America (2nd ed., pp. 1-13). Washington D.C.: Government Printing Office.

Harris, M. I. (1999). Racial and ethnic differences in health insurance coverage for adults with diabetes. Diabetes Care, 22, 1679-1682.

Hartz, A., Kent, S., James, P., Xu, Y., Kelly, M., \& Daly, J. (2006). Factors that influence improvement for patients with poorly controlled type 2 diabetes. Diabetes Research and Clinical Practice, 74, 227-232. 
Hill, P. D., Aldag, J. C., Chatterton, R. T., \& Zinaman, M. (2005). Psychological distress and milk volume in lactating mothers. Western Journal of Nursing Research, 27, 676-693.

Hinds, P., Fairclough, D., Dobos, C., Greer, R. H., Herring, P. L., Mayhall, J. et al. (1990). Development and testing of the stressor scale for pediatric oncology nurses. Cancer Nursing, 13, 354-360.

Hinds, P., Puckett, P., Donohoe, M., Milligan, M., Payne, K., Phipps, S. et al. (1994). The impact of a grief workshop of pediatric oncology nurses on their grief and perceived stress. Journal of Pediatric Nursing, 9, 388-397.

Hinds, P., Quargnenti, A., Hickey, S. S., \& Mangum, G. H. (1994). A comparison of the stress-response sequence in new and experienced pediatric oncology nurses. Cancer Nursing, 17, 61-71.

Hinds, P., Sanders, C. B., Srivastava, D. K., Hickey, S., Jayawardene, D., Milligan, M. et al. (1998). Testing the stress-response sequence model in paediatric oncology nursing. Journal of Advanced Nursing, 28, 1146-1157.

Hinds, P. S., Srivastava, D. K., Randall, E. A., Green, A., Stanford, D., Pinlac, R. et al. (2003). Testing the revised stress-response sequence model in pediatric oncology nurses. Journal of Pediatric Oncology Nursing, 20, 213-232.

Hinkle, T. (2007). West Virginia University Hospital, personal communication. 
Ho, M. P., Rumsfeld, J. S., Masoudi, F. S., McClure, D. L., Plomondon, M. E., Steiner, J. F. et al. (2006). Effect of medication nonadherence on hospitalization and mortality among patients with diabetes mellitus. Archives of Internal Medicine, 166, 1836-1841.

Holmes, D. M. (1986). The person and diabetes in psychosocial context. Diabetes Care, 9, 194-206.

Horne, R. \& Weinman, J. (1998). Predicting treatment adherence: an overview of theoretical models. In L.Myers \& K. Midence (Eds.), Adherence to Treatment in Medical Conditions (pp. 25-50). Australia: Harwood Academic Publishers.

Jeon, C.Y., Lokken, R.P., Hu, F.B., \& Van Dam, R.M. (2007). Physical activity of moderate intensity and risk of type 2 diabetes. Diabetes Care, 30, (3), 744-752.

Jorgensen, W. A., Pollvka, B. J., \& Lennie, T. A. (2002). Perceived adherence to prescribed or recommended standards of care among adults with diabetes. The Diabetes Educator, 28, 989-998.

Kavookjian, J., Elswick, B.M., \& Whetsel, T. (2007). Interventions for being active among individuals with diabetes: a systematic review of the literature. The Diabetes Educator, 33(6), 962-988.

Kemeny, M. E., Cohen, F., Zegans, L., \& Conant, M. A. (1989). Psychological and immunological predictors of genital herpes recurrence. Psychosomatic Medicine, 51, 195-208. 
Kenney, J. W. (2000). Women's 'inner balance': a comparison of stressors, personality traits and health problems by age groups. Journal of Advanced Nursing, 31, 639-650.

Kessler, T. (1998). The cognitive appraisal of health scale: development and psychometric evaluation. Research in Nursing \& Health, 21, 73-82.

Klein, S., Sheard, N., Pi-Sunyer, X., Daly, A., Wylie-Rosett, J., Kulkarni, K., et al. (2004). Weight management through lifestyle modification for the prevention and management of type 2 diabetes: rationale and strategies. Diabetes Care, 27(8), 20672073.

Knowler, W., Barrett-Connor, E., Fowler, S., Hamman, R., Lachin, J. Walker, E., et al. (2002). Reduction in the incidence of type 2 diabetes with lifestyle intervention or metformin. New England Journal of Medicine, 346, 393-403.

Krapek, K., King, K., Warren, S. S., George, K. G., Caputo, D. A., Mihelich, K. et al. (2004). Medication adherence and associated hemoglobin A1c in type 2 diabetes. The Annals of Pharmacotherapy, 38, 1357-1362.

Lazarus R.S., \& Launier, R. (1978). Stress-related transactions between person and environment. In L. Pervin \& M. Lewis (Eds.), Perspectives in International Psychology (pp. 287-327). New York: Plenum Press.

Lazarus, R. S. \& Folkman, S. (1984). Stress, appraisal, and coping. New York: Springer Company. 
Lazarus, R. S. \& Folkman, S. (1987). Transactional theory and research on emotions and coping. European Journal of Personality, 1, 141-169.

Mateo, J. F., Gil-Guillen, V. F., Mateo, E., Orozco, D., \& Carbayo, J. A. (2006). Multifactorial approach and adherence to prescribed oral medications in patients with type 2 diabetes. International Journal of Clinical Practice, 60, 422-428.

McMillan, B. (2007). MonHealth System, personal communication.

Melikian, C., White, T. J., Vanderplas, A., Dezii, C. M., \& Chang, E. (2002). Adherence to oral antidiabetic therapy in a managed care organization: a comparison of monotherapy, combination therapy, and fixed-dose combination therapy. Clinical Therapeutics, 24, 460-467.

Morningstar, B. A., Sketris, I. S., Kephart, G. C., \& Sclar, D. A. (2002). Variation in pharmacy prescription refill adherence measures by type of oral antihyperglycemic drug therapy in seniors in Nova Scotia, Canada. Journal of Clinical Pharmacy and Therapeutics, 27, 213-220.

Munkres, A., Oberst, M.T., \& Hughes, S.H. (1992). Appraisal of illness, symptom distress, self-care burden, and mood state in patients receiving chemotherapy for initial and recurrent cancer. Oncology Nursing Forum, 19(8), 1201-1209.

Murata, G. H., Shah, J. H., Duckworth, W. C., Wendel, C. S., Mohler, M. J., \& Hoffman, R. M. (2004). Food frequency questionnaire results correlate with metabolic control in insulin-treated veterans with type 2 diabetes: the diabetes outcomes in veterans study. Journal of the American Dietetic Association, 104, 1816-1826. 
Nagelkerk, J., Reick, K., \& Meengs, L. (2006). Perceived barriers and effective strategies to diabetes self-management. Journal of Advanced Nursing, 54, 151-158.

National Literacy Trust. (2007). SMOGGING - how to test the readability of text (2007). National Literacy Trust [On-line]. Available: http://www.literacytrust.org

Nelson, K. M., Reiber, G., \& Boyko, E. J. (2002). Diet and exercise among adults with type 2 diabetes. Diabetes Care, 25, 1722-1728.

Nelson, K. M., Chapko, M. K., Reiber, G., \& Boyko, E. J. (2005). The association between health insurance coverage and diabetes care; Data from the 2000 behavioral risk factor surveillance system. Health Services Research, 40, 361-372.

Nelson, K. M., McFarland, L., \& Reiber, G. (2007). Factors influencing disease self-management among veterans with diabetes and poor glycemic control. Society of General Internal Medicine, 22, 442-447.

Nesbitt, B. J. \& Heidrich, S. M. (2000). Sense of coherence and illness appraisal in older women's quality of life. Research in Nursing \& Health, 23, 25-34.

Norris, S. L., Engelgau, M. M., \& Narayan, K. M. (2001). Effectiveness of selfmanagement training in type 2 diabetes. Diabetes Care, 24, 561-587.

Norris, S. L., Lau, J., Smith, S. J., Schmid, C. H., \& Engelgau, M. M. (2002). Self-management education for adults with type 2 diabetes. Diabetes Care, 25, 11591171. 
Northouse, L., Caffey, M., Deichelbohrer, L., Schmidt, L., Guziatek-Trojniak, L., West, S. et al. (1999). The quality of life of African American women with breast cancer. Research in Nursing \& Health, 22, 449-460.

Northouse, L., Mood, D., Kershaw, T., Schafenacker, A., Mellon, S., Walker, J. et al. (2002). Quality of life of women with recurrent breast cancer and their family members. Journal of Clinical Oncology, 20, 4050-4064.

Northouse, L., Kershaw, T., Mood, D., \& Schafenacker, A. (2005). Effects of a family intervention on the quality of life of women with recurrent breast cancer and their family caregivers. Psycho-Oncology, 14, 478-491.

Oberst, M., Hughes, S., Chang, A., \& McCubbin, M. (1991). Self-care burden, stress appraisal, and mood among persons receiving radiotherapy. Cancer Nursing, 14, 71-78.

Olson, M. S., Hinds, P., Euell, K., Quargnenti, A., Milligan, M., Foppiano, P. et al. (1998). Peak and nadir experiences and their consequences described by pediatric oncology nurses. Journal of Pediatric Oncology Nursing, 15, 13-24.

Odegard, P.S., Capoccia, K. (2007). Medication taking and diabetes: a systematic review of the literature. The Diabetes Educator, 33(6), 1014-1029.

Pastors, J., Warshaw, H., Daly, A., Franz, M., \& Kulkarni, K. (2002). The evidence for the effectiveness of medical nutrition therapy in diabetes management. Diabetes Care, 25(3), 608-613. 
Pastors, J., Franz, M., Warshaw, H., Daly, A., \& Arnold, M. (2003). How effective is medical nutrition therapy in diabetes care? Journal of the American Dietetic Association, 103(7), 827-831.

Patino, A. M., Sanchez, J., Eidson, M., \& Delamater, A. M. (2005). Health beliefs and regimen adherence in minority adolescents with type 1 diabetes. Journal of Pediatric Psychology, 30, 503-512.

Pellino, T. \& Oberst, M. (1992). Perception of control and appraisal of illness in chronic low back pain. Orthopaedic Nursing, 11, 22-26.

Peyrot, M., Rubin, R. R., Lauritzen, T., Snoek, F. J., Matthews, D. R., \& Skovlund, S. E. (2005). Psychosocial problems and barriers to improved diabetes management: Results of the cross-national diabetes attitudes, wishes and needs (DAWN) study. Diabetic Medicine, 22, 1379-1385.

Polonsky, W. H., Anderson, B. J., Lohrer, P. A., Welch, G., Jacobson, A. M., Aponte, J. E. et al. (1995). Assessment of diabetes-related distress. Diabetes Care, 18, 754-760.

Ratzan, S.C., \& Parker, R.M. (2000). Introduction. In: Selden CR, Zorn, M, Ratzan, SC, Parker, RM, eds. Current Bibliographies in Medicine: Health Literacy. (NLM Pub No. CB 200-1.) Bethesda, MD: National Institutes of Health, U.S. Department of Health and Human Services, 2000 Feb. 
Resnick, H.E., Foster, G.L., Bardsley, J., \& Ratner, R.E. (2006). Achievement of American diabetes association clinical practice recommendations among U.S. adults with diabetes, 1999-2002: The national health and nutrition examination survey. Diabetes Care, 29(3), 531-537.

Rewers, M. \& Hamman, R. F. (1995). Risk factors for non-insulin-dependent diabetes. In National Diabetes Data Group (Ed.), Diabetes in America (pp. 179-220). Bethesda: National Institutes of Health.

Rhee, M. K., Slocum, W., Ziemer, D. C., Culler, S. D., Cook, C. B., El-Kebbi, I. et al. (2005). Patient adherence improves glycemic control. The Diabetes Educator, 31, 240-250.

Rosenstock, I., Strecher, V., \& Becker, M. (1988). Social learning theory and the health belief model. Health Education Quarterly, 15, 175-183.

Rothman, R.L., Malone, R., Bryant, B., Wolfe, C., Padgett, P., DeWalt, D.A., et al. (2005a). The spoken knowledge in low literacy in diabetes scale: A diabetes knowledge scale for vulnerable patients. The Diabetes Educator, 31(2), 215-224.

Rothman, R.L., Malone, R., Bryant, B., Shintani, A.K., Crigler, B., DeWalt, D.A., et al. (2005b). A randomized trial of a primary care-based disease management program to improve cardiovascular risk factors and glycated hemoglobin levels in patients with diabetes. The American Journal of Medicine, 118, 276-284. 
Rozenfeld, Y., Hunt, J.S., Plauschinat, C., \& Wong, K.S. (2008). Oral antidiabetic medication adherence and glycemic control in managed care. American Journal of Managed Care, 14(2), 71-75.

Rubin, R. R., Peyrot, M., \& Siminerio, L. M. (2006). Health care and patientreported outcomes. Diabetes Care, 29, 1249-1255.

Ruggiero, L., Glasgow, R. E., Dryfoos, J. M., Rossi, J. S., Prochaska, J. O., Orleans, C. T. et al. (1997). Diabetes self-management. Self-reported recommendations and patterns in a large population. Diabetes Care, 20, 568-576.

Saaddine, J.B., Engelgau, M.M., Beckles, G.L., Gregg, E.W., Thompson, T.J., \& Narayan, K.M. (2002). A diabetes report card for the united states: Quality of care in the 1990s. Annals of Internal Medicine, 136(8), 565-574.

Sarkar, U., Fisher, L., \& Schillinger, D. (2006). Is self-efficacy associated with diabetes self-management across race/ethnicity and health literacy? Diabetes Care, 29, 823-829.

Saydah, S.H., Fradkin, J., \& Cowie, C.C. (2004). Poor control of risk factors for vascular disease among adults with previously diagnosed diabetes. Journal of the American Medical Association, 291(3), 335-342.

Schectman, J. M., Nadkarni, M. M., \& Voss, J. D. (2002). The association between diabetes metabolic control and drug adherence in an indigent population. Diabetes Care, 25, 1015-1021. 
Schectman, J. M., Bovbjerg, V. E., \& Voss, J. D. (2002). Predictors of medication-refill adherence in an indigent rural population. Medical Care, 40, 12941300.

Sclar, D. A., Robison, L. M., Skaer, T. L., Dickson, W. M., Kozma, C. M., \& Reeder, C. E. (1999). Sulfonylurea pharmacotherapy regiment adherence in a medicaid population: Influence of age, gender, and race. The Diabetes Educator, 25, 531-538.

Seligman, H.K., Wallace, A.S., DeWalt, D.A., Schillinger, D., Arnold, C.L., Shilliday, B.B., et al. (2007). Facilitating behavior change with low-literacy patient education materials. American Journal of Health Behavior, 31, suppl 1, S69-S78.

Shinji, S., Shigeru, M., Ryusei, U., Mitsuru, M., \& Shigehiro, K. (2007). Adherence to a home-based exercise program and incidence of cardiovascular disease in type 2 diabetes patients. .International Journal of Sports Medicine, [online].

Shultz, J., Sprague, M.A., Branen, L.J., \& Lambeth, S. (2001). A comparison of views of individuals with type 2 diabetes mellitus and diabetes educators about barriers to diet and exercise. Journal of Health Communication, 6, 99-115.

Smith, C. A. \& Lazarus, R. S. (1993). Appraisal components, core relational themes, and the emotions. Cognition and Emotion, 7, 233-269.

SPSS. (2006). Statistical Package for the Social Sciences, Chicago, Illinois.

Tabachnick, B. G. \& Fidell, L. S. (2001). In R.Pascal (Ed.), Using Multivariate Statistics (4 ed.), Boston: Allyn and Bacon. 
Toobert, D. J. \& Glasgow, R. E. (1994). Assessing diabetes self-management: the summary of diabetes self-care activities questionnaire. In C.Bradley (Ed.), Handbook of psychology of diabetes (pp. 351-375). Amsterdam: Harwood Academic Publishers.

Toobert, D. J., Hampson, S. E., \& Glasgow, R. E. (2000). The summary of diabetes self-care activities measure: Results from 7 studies and a revised scale. Diabetes Care, 23, 943-950.

Tu, K. \& Morrison, E. (1996). Diabetes self-care practices, barriers, and outcomes in an indigent population: An exploratory study. Journal of Nursing Science, 1, 88-98.

Tuomilehto, J. Lindstrom, J., Eriksson, J.G., Valle, T.T., Hamalainen, H., IlanneParikka, P., et al. (2001). Prevention of type 2 diabetes mellitus by changes in lifestyle among subjects with impaired glucose tolerance. The New England Journal of Medicine, 344(18), 1343-1350.

Turner, R. C., Cull, C. A., Frighi, V., \& Holman, R. R. (1999). Glycemic control with diet, sulfonylurea, metformin, or insulin in patients with type 2 diabetes mellitus. Journal of the American Medical Association, 281, 2005-2012.

UKPDS Group (1998a). Intensive blood-glucose control with sulphonylureas or insulin compared with conventional treatment and risk of complications in patients with type 2 diabetes (UKPDS 33). The Lancet, 352, 837-853.

UKPDS Group (1998b). Effect of intensive blood-glucose control with metformin on complications in overweight patients with type 2 diabetes (UKPDS 34). The Lancet, 352, 854-865. 
Vijan, S., Stuart, N. S., Fitzgerald, J. T., Ronis, D. L., Hayward, R. A., Slater, S. et al. (2004). Barriers to following dietary recommendations in type 2 diabetes. Diabetic Medicine, 22, 32-38.

Walker, E.A., Molitch, M., Kramer, M.K., Kahn, S., Ma, Y., Edelstein, S., et al. (2006). Adherence to preventive medications. Diabetes Care, 29(9), 1997-2002.

Weinger, K, Butler, H.A., Welch, G.W., \& La Greca, A.M. (2005). Measuring diabetes self-care: A psychometric analysis of the self-care inventory-revised with adults. Diabetes Care, 28, 1346-1352.

Whittemore, R., Chase, S. K., Mandle, C. L., \& Roy, C. (2002). Lifestyle change in type 2 diabetes. Nursing Research, 51, 18-25.

Wing, R. R., Goldstein, M. G., Acton, K. J., Birch, L. L., Jakicic, J. M., Sallis, J. F. et al. (2001). Behavioral science research in diabetes. Diabetes Care, 24, 117-123.

World Health Organization. (2003). Adherence to long-term therapies: evidence for action (W-85). Switzerland.

Zinn, J. (2008). Population characteristics and service trends at a West Virginia free clinic. Unpublished master's thesis, West Virginia University, Morgantown, West Virginia, United States. 